Portland State University

PDXScholar

Summer 7-26-2016

\title{
The Mediating Effects of LMX on the Relationship Between Supervisor and Employee Age Differences, Satisfaction, and Retirement Intentions
}

Amy Christine Pytlovany

Portland State University

Follow this and additional works at: https://pdxscholar.library.pdx.edu/open_access_etds

Part of the Psychology Commons

Let us know how access to this document benefits you.

\section{Recommended Citation}

Pytlovany, Amy Christine, "The Mediating Effects of LMX on the Relationship Between Supervisor and Employee Age Differences, Satisfaction, and Retirement Intentions" (2016). Dissertations and Theses. Paper 3370.

https://doi.org/10.15760/etd.5261

This Thesis is brought to you for free and open access. It has been accepted for inclusion in Dissertations and Theses by an authorized administrator of PDXScholar. Please contact us if we can make this document more accessible: pdxscholar@pdx.edu. 
The Mediating Effects of LMX on the Relationship Between Supervisor and Employee

Age Differences, Satisfaction, and Retirement Intentions

by

Amy C. Pytlovany

A thesis submitted in partial fulfillment of the requirements for the degree of

\author{
Master of Science \\ in \\ Applied Psychology
}

Thesis committee:

Donald Truxillo, Chair

Todd Bodner

Berrin Erdogan

Portland State University

2016 


\begin{abstract}
Increasing age heterogeneity within organizations is pressing researchers to better understand the effects of a multigenerational workforce, teams, and dyads. In response to this, the present research aimed to investigate the effect of employee and supervisor age (in)congruence in relation to job and life satisfaction, as well as retirement intentions, all mediated by leader-member exchange (LMX), using a time-lagged design. Two different theoretical foundations were investigated. Based on the relational demography literature, better outcomes were expected to be associated with age similarity. Theories about implicit expectations relating age and social role guided hypotheses suggesting that beyond just similarity or difference, the direction of age differences would matter. Based on traditional social assumptions that age is associated with experience and wisdom, it was expected that work outcomes would be better when the supervisor was older than the employee, and worse when the supervisor was younger than the employee. Results did not support any of the proposed hypotheses, with the exception of the established relationship between LMX and job satisfaction. However, response surface graphs and polynomial regression results directed post hoc analyses which did reveal a main effect of supervisor age on LMX and an indirect effect of supervisor age on Time 2 job satisfaction through Time 1 LMX. Employees in this sample reported higher quality LMX when supervisors were younger, regardless of employee age, and in turn employees with younger supervisors reported higher job satisfaction. These results and the trends depicted by response surface graphs are discussed in relation to implications for research and practice.
\end{abstract}




\section{Acknowledgements}

I would like to acknowledge and thank my committee, Drs. Donald Truxillo, Todd Bodner, and Berrin Erdogan, as well as Dr. Leslie Hammer, for the opportunities and support they have provided me over the past several years. I would also like to acknowledge the Oregon Healthy Workforce Center (OHWC) and the National Institute of Occupational Safety and Health (NIOSH; grant U19OH010154) for their role in making the Safety and Health Improvement Program (SHIP) possible. In addition to providing the data for this study, the experiences afforded me through this project have been invaluable. I would also like to express gratitude to my friends, family, and other Psychology Department professors and colleagues, for their encouragement, support, and inspiration. 


\section{Table of Contents}

Abstract




\section{List of Tables}

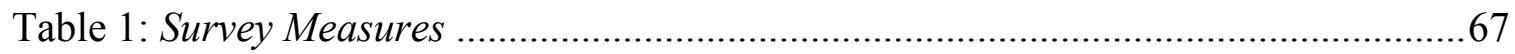

Table 2: Descriptive Statistics, Correlations, and Alpha Reliabilities..............................68

Table 3: Cross-level Polynomial Regression and Response Surface Test Results ............70 


\section{List of Figures}

Figure 1. Changes over time in the age distribution of the workforce...............................71

Figure 2. Workforce age distribution in 1994 as compared to projection for 2024 ...........72

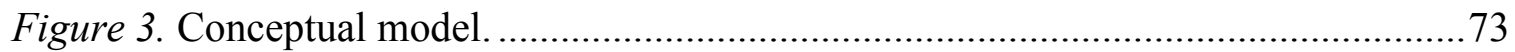

Figure 4. Example response surface for congruence effect …………………………......74

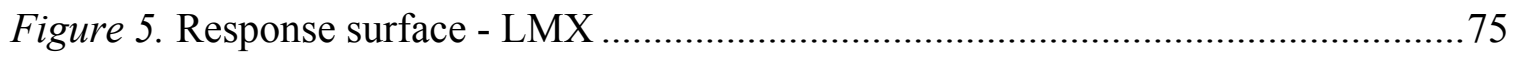

Figure 6. Response surface - Job Satisfaction...........................................................

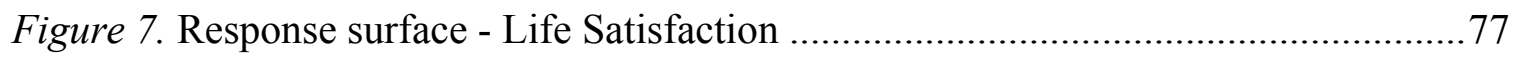

Figure 8. Response surface - Retirement Intentions .......................................................78 


\section{Introduction}

Populations within industrialized nations around the globe are aging. This is a result of the "Baby Boom" following World War II, a post-Baby Boom decline in fertility rates, and increased longevity due to medical advances and lifestyle changes. In the United States, it is projected that $38.2 \%$ of the population will be 55 years of age or older by 2024 , compared with $34.2 \%$ in 2014 and $28.4 \%$ in 2004 (Toossi, 2015). This demographic shift, sometimes called the "silver tsunami", is expected to continue and will have an increasingly important impact at multiple levels of society.

Organizations are impacted because an aging population indicates a demographic shift in the workforce. In fact, the U.S. Bureau of Labor Statistics (BLS) reports that the proportion of workers 55 years of age and older has nearly doubled in the past 30 years from $11.9 \%$ in 1994 to $21.7 \%$ in 2014 . This trend will continue based on BLS projections that nearly $25 \%$ of the workforce will be age 55 or older by the year 2024 (Toosi, 2015). Figure 1 and Figure 2 provide visual representation of these workforce age distribution changes and projections. The shift in workforce age distribution is the result of aging Boomers (a large generational cohort) and retirement occurring at later ages than in the past. The growing proportion of older workers within organizations means that increasingly employees are working side-by-side with those from a different generation. Based on this increasing phenomenon, it is understandable that organizations and researchers want more information about the effects of workplace age diversity. It should be noted that diversity can be conceptualized in many ways (e.g., Harrison \& Klein, 2007). The use of the term age diversity here refers to age dissimilarity. 
Research shows that organizational diversity is associated with both positive and negative work-related processes and outcomes. For example, diversity is associated with increased competitive advantage through enhanced creativity and innovation, but can also have detrimental effects such as low morale, absenteeism, and low quality work if diversity is poorly managed (Bassett-Jones, 2005). Using the definition of diversity applied here, Kunze, Böhm, and Bruch (2011) demonstrated that higher levels of age diversity within an organization negatively impacted performance through higher perceptions of age discrimination climate. Perceptions of age discrimination climate related to potential for discrimination in performance assessment, career opportunities, allocation of tasks, professional and personal development, and leadership behavior. Prejudice and discrimination in the workplace are influenced by stereotypes and biases (Cadiz, Pytlovany, \& Truxillo, in press), and we know that negative stereotypes about both older and younger generations persist despite evidence to the contrary (Costanza, Badger, Fraser, Severt, \& Gade, 2012; Posthuma \& Campion, 2009). These findings indicate that age diversity and age-related biases have important implications for interpersonal relationships and outcomes at work. Specific to leaders and followers, previous research has reported supervisor and employee age dissimilarity is associated with numerous negative outcomes including biased performance ratings (Collins, Hair \& Rocco, 2009; Judge \& Ferris, 1993), higher rates of turnover (O'Reilly, Caldwell, \& Barnett, 1989), and lower organizational commitment (Shore, Cleveland, \& Goldberg, 2003). With organizational age diversity increasing, business leaders will need to take proactive steps to reduce harmful cross-generational stereotypes, prejudice, and 
discrimination. As noted above, managing organizational diversity is important for individual and organizational well-being (e.g., Bassett-Jones, 2005).

An additional consideration related to an aging workforce is the increasing proportion of employees eligible for retirement. As a growing proportion of the workforce reaches retirement age, organizations risk mass exodus of valuable employees. The experience, institutional knowledge, and critical business partnerships that potentially disappear when older workers retire can be of great cost to the efficiency and effectiveness of organizations (Beehr, 2014). Furthermore, the cohort that immediately follows the Boomers, Generation X, is much smaller in comparison meaning that employees from younger generations may be fast-tracked into leadership positions without the opportunity to gain sufficient experience. Retirement decisions also have a large social impact because workers who retire later in life continue to contribute to, rather than draw from, social security. Additionally, financial and health strains associated with transition to retirement indicate a need to better understand decisions relating to retirement and how this transition can be facilitated (Szinovacz, 2003).

These data and this literature illustrate the increasing need to identify how age diversity impacts employees, dyads, teams, and organizations. Research is needed to inform ways of promoting the positive aspects of age diversity within organizations and also for mitigating the negative consequences. Further, organizations need guidance about leverage points to help prolong workers' ability and desire to remain in the workforce. Although a growing literature exists on age-related effects at work, there is still much left unanswered due to unexplored questions or inconclusive evidence. One 
such area relates to the effects of age dissimilarity within teams in general, and within supervisor/employee dyads specifically.

Researchers that have investigated supervisor and employee age dissimilarity tend to focus on simple nondirectional calculations of age difference, meaning a 15-year difference is examined in the same way regardless if the supervisor is 15 years older or younger than the employee (for exceptions see Perry, Kulik, \& Zhou, 1999; Vecchio, 1993). Empirical findings of age-related effects at work tend to be marginal as compared to other demographic differences such as race or gender (e.g., Thatcher \& Patel, 2011), and the studies investigating nondirectional age differences within teams and dyads have revealed inconsistent results. Harrison, Price, Gavin, and Florey (2002) suggest failure to look at perceptions of diversity (as opposed to actual differences), or to differentiate between surface-level verses deep-level diversity could explain small effect sizes and mixed findings. Surface-level diversity refers to "high visibility" differences such as age, gender, and race, whereas deep-level diversity is related to differences that are more psychological in nature such as personality, values, and beliefs (Harrison et al., 2005).

Another explanation could be that most research has not examined the direction of the age difference, that is, which member of the dyad is older or younger. Status incongruence is said to exist when supervisors are lacking in any one or more of the following characteristics: most expert, most experienced, best paid, and oldest member of the team (Vecchio, 1993). The directional operationalization of age differences acknowledges implicit assumptions that older, more experienced employees should supervise younger, less experienced employees, and that violation of these expectations is 
likely to produce different results than when the same age difference exists for supervisors and employees whose age dissimilarity is congruent with status norms. Examination of directional differences when investigating supervisor/employee age differences is uncommon, and needs to be explored further. This is a particularly relevant phenomenon to study as the prevalence of older employees reporting to younger supervisors is increasing along with organizational age heterogeneity.

It is important to again mention the methodological approaches that have been used to investigate supervisor and employee age similarity (dissimilarity). All studies cited in this paper relied on use of difference scores, and I was unable to locate any studies using more modern alternatives. It is argued that difference scores result in low reliability, confounded effects, and dimensional reduction, and that polynomial regression analysis supplemented by response surface methodology is more appropriate for examining the joint effects of two predictor variables (such as employee and supervisor age) on a third outcome variable (Edwards, 2002). This method is now commonly used to examine effects of person and environment fit (e.g., Yang, Che, \& Spector, 2008), and has also been used to investigate joint effects across a multitude of constructs including congruence between individual and organizational values (Edwards \& Cable, 2009), individual and work group hurriedness (Jansen \& Kristoff-Brown, 2005), and leader/follower proactive personality (Zhang, Wang, \& Shi, 2012). Introduction of this analytical method is needed in the age difference literature and was used in the current study. 
From a more theoretical perspective, this study contributes to the current literature by not only investigating nondirectional age differences from a similarity bias perspective, but also through exploration of directional age differences within a status incongruence framework. These two conceptualizations of supervisor and employee age difference were examined in relation to leader-member exchange (LMX), job satisfaction, life satisfaction, and retirement intentions. Supervisor/employee nondirectional age differences have been examined in previous studies in relation to job satisfaction and LMX, however conflicting results have emerged (Epitropaki \& Martin, 1999; Pelled \& Xin, 2000; Schaffer \& Riordian, 2013; Shore et al., 2003). This study helps to clarify these findings, and also provides unique information in regard to life satisfaction and retirement intentions.

Further, this study investigated the relatively unexamined effects of directional age differences within supervisor/employee dyads, potentially highlighting an organizational scenario that needs to be considered when structuring teams. Vecchio (1993) did investigate directional age differences in relation to LMX, however this is the only known study to look at this link. His research did not measure LMX using the most updated scale, and his findings were in the unexpected direction. The current study further investigated this phenomenon, and did so using the LMX7 tool recommended by Graen and Uhl-Bien (1995). The results relating directional age differences to job satisfaction, life satisfaction, and retirement intentions are unique additions to the literature. 
Exploration of the link between LMX and life satisfaction answers a call for investigation of life satisfaction within an organizational context, and with application of leadership theories (Erdogan, Bauer, Truxillo, \& Mansfield, 2012). Only one known study has examined LMX with life satisfaction (Kacmar, Carlson, \& Brymer, 1999). This study focused on examining the antecedents (including LMX) and consequences (including life satisfaction) of multiple facets of commitment using a cross-sectional design. Although a significant correlation of .22 was reported $(p<.05)$ between LMX and life satisfaction, the direct link was not analyzed. Further, no studies were located looking at LMX in direct relation to retirement attitudes, indicating another gap in the literature given the need for organizations and society to support people working longer. In sum, this study addressed gaps in the literature pertaining to LMX and these outcomes, and aimed to help provide organizations with a potential leverage point for improving employee life satisfaction and retaining older workers. LMX was measured at Time 1, and the outcomes were measured six months later (Time 2). Additionally, LMX (Time 1) was investigated as a mediator between both conceptualizations of age differences and Time 2 job satisfaction, life satisfaction, and retirement intentions. The time-lagged design used in this study allows for stronger conclusions to be inferred about the causality of effects, as compared to more commonly used cross-sectional designs.

Lastly, the sample used for this study was construction workers - an occupational group in need of targeted research as recommended by the National Occupational Research Agenda (NORA; 2008). Construction workers face unique challenges in their work such as high physical demands and increased susceptibility to health issues 
(Bodner, Kramer, Bradford, Hammer, \& Truxillo, 2014; Peterson \& Zwerling, 1998). Because declines in physical ability and health are often associated with aging, these work characteristics may cause age to be especially salient within this population. The findings from this study could be particularly useful for identifying was to help construction workers improve work processes and outcomes.

The theoretical foundations for this study follow. First, frameworks that inform how demographic similarity (or dissimilarity) influence individual attitudes and behavior, as well as how implicit assumptions about age and social role are likely to impact supervisor and employee dyads will be discussed. Next, LMX theory in relation to this proposal will be presented. Theoretical approaches to studying the outcomes of interest will be discussed, and the proposed relationship between each with both conceptualizations of age difference, and LMX will be summarized. The specific hypotheses explored will be outlined before moving on to the method and results. Finally, the document will conclude with a discussion of implications, limitations, and future directions. The conceptual model, with LMX mediating the relationship between age dissimilarity and attitudinal outcomes of job satisfaction, life satisfaction, and retirement intentions measured six months later, is presented in Figure 3.

\section{What Do "Younger Worker" and "Older Worker" Mean?}

Before proceeding, it is important to note a persistent challenge in age-related research, which is in identifying where to the draw the boundary lines between what is considered young, old, or middle-aged. Numerous factors influence these perceptions including, for example, age-related stereotypes associated with the job or industry, or the 
age at which legal protections become applied. Moreover, as people live longer and continue to thrive later into life, it is also possible that these boundaries are shifting (Truxillo, Finkelstein, Pytlovany, \& Jenkins, 2015). For the research questions in this study "younger" or "older" does not refer to a particular age, but instead is a comparison to the self as a referent. In other words, is the supervisor younger or older (or the same age) than the employee, and if so, how great is this difference?

\section{Understanding Supervisor/Employee Age Differences}

\section{Relational Demography}

One commonly used framework to explain how age differences influence work processes and outcomes is relational demography. Thatcher (1999) defined relational demography as the "degree to which an individual is different from other members of the team on various demographic characteristics" (p. 97), but this framework has also been applied to exploration of dyad differences (Perry et al., 1999; Tsui \& O’Reilly, 1989; Tsui, Xin, \& Egan, 1995). Relational demography research investigates the effects of demographic differences (e.g., age, race, gender) on individual-level outcomes such as work attitudes or behaviors. This research is based on three key theoretical foundations: social identity theory (Tajfel, 1974), social categorization theory (Turner, 1985), and the similarity-attraction paradigm (Byrne, 1971).

Social identity theory maintains that a person defines their identity by comparing their social role to that of others. Easily accessible salient personal characteristics (such as age) are used to differentiate in- and out-groups, and in-group membership is used to derive self-concept. Because people are motivated to enhance and maintain a positive 
self-concept, more favorable evaluations are bestowed upon similar others, and attempts are made to distinguish one's self from those deemed dissimilar (Tajfel \& Turner, 1986).

Social-categorization theory explains the cognitive process of depersonalization that occurs when an individual's identity becomes defined according to a collective identity determined by social group membership. Individuals strive to increase alignment with, and obtain approval from, those who are similar, and similar others provide validation about the way one interprets and relates to the world (Turner \& Oakes, 1989). Interactions with out-group members are thought to create anxiety and lead to avoidance behaviors, and "the mere presence of an out-group is sufficient to provoke intergroup competitive or discriminatory response on the part of the in-group" (Tajfel \& Turner, 1986, p. 415).

Byrne's (1971) similarity-attraction paradigm further describes the association between similarity and interpersonal attraction. Byrne suggested that individuals are likely to have an increased attraction to, greater liking of, and more positive beliefs about, those who are attitudinally similar. Research based on this theory has demonstrated support across a wide range of similar characteristics (including demographics), people, and outcomes (e.g., Osbeck, Moghaddam, \& Perreault, 1997; Senn, 1971; Tsui \& O’Reilly, 1989).

In sum, theory indicates supervisor and employee dyads may use demographic characteristics, such as age, to establish in-group and out-group membership, and that this affiliation will influence inferences made about self and others. Dyads similar in age are likely to experience stronger levels of attraction and liking, more positive evaluations of, 
and more positive affect toward one another than dyads dissimilar in age. Dissimilar pairs are expected to encounter more negative feelings, biases, and efforts to avoid interaction.

As mentioned previously, some research suggests the importance of distinguishing between surface-level verses deep-level characteristics when studying effects related to individual differences (Harrison, Price, \& Bell, 1998; Harrison et al., 2002). Surface-level characteristics generally refer to demographic traits that can be quickly and easily observed, and therefore provide the basis for initial social judgments. Deep-level characteristics refer to psychological qualities such as personality traits, values, attitudes, and beliefs. The distinction between these levels is important because over time, as more information is gleaned about social partners, deep-level characteristics are more strongly related to intergroup outcomes (e.g., social integration), and the effects of surface-level characteristics are mitigated (Harrison et al., 2002). Although age, being a demographic categorization, is generally considered a surface-level trait, it may also be associated with deep-level effects due to generational and developmental differences in values, attitudes, and behaviors (Arsenault, 2004; Lawrence, 1984).

\section{Current Research on Nondirectional Age Differences}

As mentioned previously, studies investigating the effects of age similarity within teams and leader/follower dyads have revealed mixed results. Dissimilarity has been related to reduced organizational commitment (Shore et al., 2003), and objective performance (Thatcher, 1999), as well as increased absenteeism (Cummings, Zhou, \& Oldham, 1993), turnover intentions (Tsui, Egan, \& O'Reilly, 1992), and actual turnover (O'Reilly et al., 1989; Wagner, Pfeffer, \& O'Reilly, 1984). In line with the presented 
theories, research conducted by Judge and Ferris (1993) demonstrated age differences between supervisors and employees were related to lower supervisor affect toward employees and worse ratings of employee job performance by the supervisor. Additionally, Fagenson-Eland, Baugh, and Lankau (2005) reported greater discrepancy in perceptions of developmental support when mentors and protégés differed in age.

In contrast, researchers have reported age dissimilarity was not related to LMX (Green, Anderson, \& Shivers, 1996) or employee perceptions of discrimination or exclusionary treatment from the supervisor (Schaffer and Riordian, 2013). Pelled and Xin (2000) reported contradictory findings in a study that found age differences impacted LMX quality in a Mexican sample, but not in their U.S. sample, indicating supervisor/employee age differences may only impact LMX in some populations. Another contradiction is found in comparing results of studies investigating dyadic age differences and job satisfaction. Using hierarchical regression, with age as a continuous variable, Shore and colleagues (2003) found that the interaction of manager and employee chronological age accounted for significant variance in job satisfaction. These results conflict with research by Epitropaki and Martin (1999) who used a median split to dichotomize age into younger and older, and did not find the link with job satisfaction to be significant. These inconsistent findings may be due to the different methods used to operationalize age. In sum, inconsistent findings indicate age similarity (dissimilarity) matters, but only under some conditions.

\section{Implicit Theories of Supervisor/Employee Role Expectations}


Looking beyond simple calculations of age differences may help explain more of the story. Because age is a salient characteristic used to categorize people, it is also used to match individuals with expected social roles and statuses, and is prescriptive of socially "appropriate" and "acceptable" behaviors. These expectations are influenced by the historical norms within society (Biddle, 1986) and organizations (Perry, 1994).

For example, research suggests that clear age-related norms exist regarding career status expectations. The literature on implicit career timelines suggests that employees who are promoted at a rate consistent with others their age are considered "on time" in relation to the expected career timetable. Those who move up through the organizational ranks quicker are "ahead", and those who maintain lower career status than their cohort are believed to be "behind" (Lawrence, 1988). When supervisor and employee age differences do not align with implicit career timelines, multiple interpretations are possible. One interpretation is that a younger "supervisor may be perceived as an exceptional individual who transcends common organizational role and status norms." A second interpretation is that "employee[s] may perceive [a younger] supervisor as having attained a position that he or she does not deserve." The third is that an older "employee may be perceived as slow in terms of advancement and development," (Tsui et al., 1995, p. 113). Any of these interpretations will have important implications for supervisor and employee interactions, attitudes, and behaviors, but the last two are likely to be most problematic.

Implicit leadership theories (ILTS) explain how perceptions and interpretation of leader behaviors are guided by ingrained assumptions about the traits and characteristics 
a leader should possess (Lord \& Maher, 1991). This not only includes personality characteristics and expected behaviors (Lord, De Vader, \& Alliger, 1986; Offermann, Kennedy, \& Wirtz, 1994), but also includes demographic traits (Epitropaki \& Martin, 2005). Additionally, similar to how employees use leader prototypes to cognitively evaluate their supervisors, supervisors are guided by implicit assumptions and expectations regarding qualities of effective employees. These implicit performance theories serve as the basis for judging employees (Lord \& Maher, 1991). When leader and follower characteristics do not align with cognitive prototypes negative attitudes and behaviors are expected (prototype matching, Perry, 1993).

Historically, older, more experienced supervisors have managed younger, less experienced employees and this established precedent influences biases about which age groups should fill leader and follower roles. Specifically, these theories suggest implicit assumptions exist that supervisors should be older than younger employees, and that negative consequences are likely to occur when assumptions about age and organizational role are violated.

\section{Current Research Informing Directional Age Differences}

Lawrence (1984) reported employees who perceived they were "behind" on the implicit career timeline in comparison to others their age were less work-oriented and reported lower job satisfaction. It is possible that age-related status incongruence make these perceptions more salient. Kearney (2008) revealed the likelihood of troubled work processes associated with age-related status incongruence in a study that demonstrated transformational leadership was associated with team performance, but only with the 
manager was older than most team members. Additionally, Collins and colleagues (2009) reported that older workers have lower expectations and provide lower ratings of leadership behavior for younger supervisors than do younger workers with the same supervisor. Finally, Shore and colleagues (2003) revealed younger managers provided significantly more developmental opportunities, and higher ratings of promotability, to younger workers, as compared to older workers. These empirical findings can be explained by implicit assumptions described by the theories presented and indicate agerelated status incongruence is likely a critical component to examine when looking at work-related outcomes associated with supervisor and employee age differences.

\section{Leader-Member Exchange (LMX) as a Mediator}

Leader-member exchange (Graen, Novak, \& Sommerkamp, 1982; Graen \& Scandura, 1987; Graen \& Uhl-Bien, 1995), stemming from vertical dyad linkage (VDL) theory (Dansereau, Graen, \& Haga, 1975), provides a framework within which investigations of supervisor and employee age differences can be explored. LMX theory explains that relationships between leaders and followers are unique for each dyad, and are developed through the social exchange of both partners during a "role making" process. A key element is the reciprocal influence of both members, and the transition from transactional leadership to transformational leadership for the in-group employees with whom the LMX relationship develops (Graen \& Uhl-Bien, 1995).

LMX relationship development involves three stages. The first stage includes introduction and assessment. Interactions remain formal as roles and expectations are established. Next, enhancement of the relationship occurs when a work-related exchange 
offer is made (by either party), and the offer is accepted, and reciprocated. In this second stage, the relationship is being tested and roles are being negotiated. Although there is an increase in sharing of resources and information, exchanges are still limited. A mature partnership, or high-quality LMX relationship, occurs when dyads have progressed to the third stage, in which mutual respect, trust, and obligation are established. These dyads experience reciprocal influence and exchange, loyalty, support, increased sharing of resources, and internalization of common goals (Graen \& Uhl-Bien, 1995). Offer initiation and acceptance is contingent upon three things - mutual respect for the capabilities of the other, an expectation that reciprocal trust will be developed, and beliefs that career-oriented social exchanges will lead to a partnership of mutual benefit.

Biases associated with age group membership and role expectations are likely to influence initiation and acceptance of offers. For example, because individuals avoid and compete against out-group members, quality LMX relationships are not likely to be initiated between employees and supervisors from different age groups. Moreover, positive attributions of in-group members for similar aged dyads are likely to increase the initiation of LMX and progression to a high quality relationship. Also note how the dimensions of a high-quality LMX relationship, such as reciprocal influence and internalization of common goals, are similar to those described for in-group members by social categorization theory (Turner \& Oakes, 1989) indicating similar aged dyad are more likely to have this type of relationship.

Assumptions related to implicit career timetables, and appropriate leader/follower characteristics could hinder offer initiation and LMX relationship development between 
dissimilar aged dyads. Older employees may not respect younger supervisors, believing they are undeserving of the role (Tsui et al., 1995), and younger supervisors may buy into stereotypes that older workers are poorer performers, resistant to change, and difficult to train (Posthuma \& Campion, 2009). LMX exchange offers are not likely to be made because partners think they have little to gain from developing the relationship. Conversely, according to implicit leadership and performance theories, LMX relationships are more likely to be initiated when age differences align with traditional status norm. For example, younger employees may see older supervisors as offering valuable personal and professional resources including, experience and wisdom, that can enable career development, and older supervisors may be driven by generativity motives to support the growth and success of younger employees (e.g., Clark \& Arnold, 2008).

Changes across the life span such as shifts in physical health, cognitive abilities, personality, and motivation indicate employees of different ages may have different needs (Truxillo, Cadiz, \& Rineer, 2014). Moreover, research shows that responses to work scenarios differ across age groups. For example, younger and older employees vary in their response to performance appraisals. Older workers respond more positively to favorable feedback and to feedback that is delivered in a thoughtful and considerate manner, whereas the quality of feedback (e.g., relevant, specific, informational) is more important to younger workers (Wang, Burlacu, Truxillo, James, \& Yao, 2015). These age-related differences suggest managing employees within age-diverse teams may present a challenge, and this may most difficult when managing those who are different in age from one's self. 
Decades of research have demonstrated the effectiveness of high-quality LMX relationships on work-related outcomes including performance (e.g., Dunegan, Duchon, \& Uhl-Bien, 1992; LaGrace, 1990) job satisfaction (e.g., Erdogan \& Enders, 2007;

Graen, Novak, \& Sommerkamp, 1982; Turban, Jones, \& Rozelle, 1990), commitment (Nystrom, 1990; Seers \& Graen, 1984), turnover (e.g., Ferris, 1985; Vecchio, Griffeth, \& Hom, 1986), and career progress (e.g., Bell, 1994; Graen \& Wakabayshi, 1993). However there is a lack of research regarding age and LMX. Recently, Erdogan and Bauer (2014) reviewed the LMX literature and reported an inconsistent relationship between demographic variables and LMX, with correlations between LMX and age ranging from .08 to .19 across studies. Moreover, Truxillo and Burlacu (2015) reviewed the research pertaining specifically to age and LMX and noted that the role of age differences on the LMX relationship has received little study.

Although some research has investigated the impact of supervisor/employee age dissimilarity on LMX (Green, et al., 1996; Pelled \& Xin, 2000; Schaffer \& Riordian, 2013), these are just a few studies and results were contradictory. The scarcity of conclusive research on this topic, particularly the scant attention paid to directional age differences, along with the potential importance given increasing age heterogeneity within organizations, calls for researchers to help clarify if, when, and why supervisor and employee age differences affect LMX. The current study contributes to addressing this gap in the literature. 
LMX is also expected to predict job satisfaction, life satisfaction, and retirement intentions, and that LMX mediates the relationship between age differences and these outcomes. A discussion of how each of these relate to age differences and LMX follows.

\section{Distal Outcomes: Job Satisfaction, Life Satisfaction, and Preference to Retire}

\section{Job Satisfaction}

Job satisfaction was defined by Locke (1976) as "a pleasurable or positive emotional state resulting from the appraisal of one's job or job experiences," (p. 1300), and is influenced by both thoughts (cognitive component) and feelings (affective component) an individual has about their job. Job satisfaction is one of the most frequently examined constructs in organizational research, and has been investigated as a predictor, correlate, and consequence across a wide range of work phenomena. This construct has been examined both broadly with global measures of overall job satisfaction, and more narrowly through investigation of job satisfaction facets. One commonly used measure of job satisfaction is the Job Descriptive Index (JDI; Smith, Kendall, \& Hulin, 1969) which includes five dimension of job satisfaction including nature of the work itself, supervision, coworkers, pay, and promotion. However job satisfaction facets are not limited to these and can include any aspect of the job. Other commonly explored dimensions include work conditions, growth opportunities, recognition, and security (Spector, 1997). Examining facets is useful when the research goal is to assess which aspects of a job influence satisfaction, however global measures of job satisfaction are more appropriate for investigating overall attitudes about one's job. 
General job satisfaction is the outcome of interest in this this study, and therefore a global measure will be used.

A commonly used theoretical framework for investing job satisfaction is Herzberg's (1966) motivation-hygiene theory, also called the two-factor theory. Herzberg proposed that work dimensions could be dichotomously categorized into motivational factors and hygiene factors. Motivators relate to satisfying work elements such as recognition, responsibility, and achievement. Hygiene factors, associated with dissatisfaction, include supervisor relationship, work conditions, and status. Motivation and hygiene factors are impacted by age differences and therefore age differences will be related to job satisfaction. Some examples include biased supervisor ratings of performance (Judge \& Ferris, 1993), a potential motivator, and role ambiguity (Tsui, \& O’Reilly, 1989), a potential hygiene factor. Additionally, job satisfaction could be impacted if a younger supervisor resisted providing older workers with high levels of responsibility (motivator) due to biases that older workers have less ability, and through violation of age-related status norms (hygiene factor).

Hackman and Oldham's (1976) job characteristics model is another approach to understanding job satisfaction. This model explains how job characteristics, including skill variety, task identity, task significance, autonomy, and feedback can enhance job satisfaction through their impact on critical psychological states. Job satisfaction will be experienced according to the extent to which these characteristics contribute to employee perceptions that they are learning, personally responsible for outcomes, and contributing to meaningful work (Hackman \& Oldham, 1976). One example of how this model can be 
applied to the current study comes from empirical findings that younger managers provide more learning opportunities to young employees, as compared to older employees (Shore et al., 2003).

Affect based theories include affective events theory (AET; Weiss \& Cropanzano, 1996) and range of affect theory (Locke, 1976). AET suggests that affective responses to work events directly impact work attitudes, including job satisfaction. Relational demography theories indicate similar aged dyads will experience more positive affect, are likely to interpret the other's behavior more favorably, and thus in conjunction with AET, should report higher job satisfaction. Locke's affect theory posits that satisfaction occurs when one's actual job situation matches with their ideal. Therefore, when supervisor and employee status aligns with implicit assumptions about career timetables, job satisfaction should be greater.

A final theory to be presented here is equity theory (Adams, 1963; 1965). This theory is applied to job satisfaction such that employee satisfaction, or dissatisfaction, will be proportional to the alignment, or discrepancy, between inputs (e.g., pay, recognition) and outputs (e.g., time, effort). Perceptions of equity are further determined by comparison of one's ratio to the ratio of others. For instance, if an employee feels that a co-worker is doing the same amount of work, but is receiving more reward, inequity will be perceived and the employee is more likely to be dissatisfied. Research reports of differences in performance (Judge \& Ferris, 1993) and promotability ratings (Shore et al., 2003) associated with nondirectional and directional supervisor/employee age differences 
indicate inequity may be experienced by employees from dissimilar aged dyads, and consequently they will experience lower job satisfaction.

The relationship between LMX and job satisfaction has been well established (e.g., Dulebohn, Bommer, Liden, Brouer, \& Ferris, 2012). As argued above, nondirectional and directional age differences will impact LMX relationship development such that similarity and adherence to traditional age-related status norms will be associated with higher-quality LMX. To reiterate, positively biased perceptions of similar-aged dyad partners will lead to greater trust and greater attraction, leading to increased likelihood of LMX exchange offers and relationship development. In turn, job satisfaction will be higher for employees with supervisors of similar age. When age differences do exist, employees who are younger than their supervisor will perceive that they can benefit from the experience, wisdom, and network of an older supervisor and therefore will be more likely to put forth efforts to develop a quality LMX relationship than employees who have supervisors younger than them. Furthermore, older supervisors may be motivated to support a younger employee's personal and professional career growth and thus a LMX relationship will be initiated and sustained. As the result of having a high-quality LMX relationship, employees with older supervisors will report higher job satisfaction.

Spector (1997) argues that the importance of job satisfaction can be seen from both a humanitarian and utilitarian perspective. First, treating people fairly and with respect is the right thing to do. Second, job satisfaction can lead to increased productivity and organizational functioning. Third, assessments of employee job satisfaction across an 
organization can be used as a diagnostic tool to identify where problems may be occurring. As mentioned earlier, there have been inconsistent findings when researchers have looked at supervisor/employee age similarity in relation to job satisfaction (Epitropaki \& Martin, 1999; Shore et al., 2003). The theories discussed suggest there are multiple pathways through which supervisor/employee age differences may impact job satisfaction. Given the individual- and organizational-level importance of this construct, and with organizational age heterogeneity steadily increasing, clarification of this relationship is needed. This study helps to do this.

\section{Life Satisfaction}

Subjective well-being is comprised of three dimensions: presence of positive affect, absence of negative affect, and life satisfaction. In contrast to the emotional aspects of the first two components, life satisfaction is a cognitive, judgmental process. Satisfaction is determined through assessment of one's life circumstances in comparison to a perceived standard (Diener, Emmons, Larsen, \& Griffin, 1985).

Theoretical approaches to studying life satisfaction include a top-down approach and a bottom-up approach. From the top-down, life satisfaction is viewed as a function of stable personal traits. Person-specific characteristics, such as personality, influence how people interpret life events, and these interpretations consequently impact satisfaction with life. From the bottom-up, life satisfaction is determined by evaluating the satisfaction derived from multiple life domains. These might include work, family, health status, and leisure activities. Satisfaction in all domains is necessary for life satisfaction to be experienced, however valance of each domain will vary across individuals, and thus 
will be weighted differently in assessments of a satisfactory life (Diener et al., 1985; Erdogan et al, 2012).

Work is thought to influence life satisfaction through need fulfillment, including financial, interpersonal, and status needs. Supervisors are often in an ideal position to help provide or facilitate satisfaction of these needs. The negative attitudes and behaviors associated with age differences indicate employees who are similar in age to their supervisor may have more opportunities to have their needs fulfilled and consequently are likely to report higher life satisfaction. For instance, directional age differences may negatively impact satisfaction of financial needs as illustrated by studies demonstrating status incongruence is related to lower ratings of promotability (often associated with pay raises) for older employees by younger supervisors, and lower ratings of supervisor effectiveness (which may influence promotion decisions) for younger supervisors by older employees (Collins et al., 2009; Shore et al., 2003). Additionally, supervisors can be a great source of personal support when relationships are positive, but relationship development may be hindered by both directional and nondirectional age differences. Finally, supervisor/employee status in relation to the implicit career timetable (Lawrence, 1988 ) is likely to influence life satisfaction for older workers.

Another antecedent of life satisfaction includes opportunities for mindful activity, such as having challenging and meaningful work, as well as satisfaction with growth and development options. Leaders again play a critical role in creating work with these characteristics. Mentoring relationships are one way leaders can provide both growth opportunities and meet interpersonal needs. However, these relationship processes can be 
disrupted by supervisor/employee age differences as illustrated by Fagenson-Eland and colleagues (2005) who reported greater age differences between mentors and protégés were associated with greater disagreement about the amount of developmental support being provided. Additionally, younger supervisors may be more likely to believe stereotypes about older workers being difficult to train (Posthuma \& Campion, 2009) and consequently provide fewer growth opportunities to older employees. Indeed, research has shown that this occurs (Shore et al., 2003).

Job tensions are another factor that can influence life satisfaction. The jobdemand resources model (JD-R; Demerouti, Bakker, Nachreiner, \& Schaufelli, 2001) is one framework that can be used to examine this link. It has been used to demonstrate that job demands, such as workload and time pressure, are negatively related to life satisfaction through exhaustion. Resources, including supervisor support and feedback, are positively related to life satisfaction through engagement (Demerouti, Bakker, Nachreiner, \& Schaufelli, 2000). Biased supervisor attitudes and behaviors toward employees resulting from in-group and out-group membership, as well as implicit role assumptions, are likely to influence level of demands and provision of resources, and consequently should impact life satisfaction. Additionally, life satisfaction has been negatively associated with supervisors, such that they can be a potential source of daily hassle (Mayberry, Neale, Arentz, and Jones-Ellis, 2007). Therefore, life satisfaction may be higher for employees who are similar in age to their supervisor because they are less likely to perceive supervisor interactions as a hassle. 
Because leaders control many of the factors predicting life satisfaction, employees with high-quality LMX relationships will be more likely to have positive work experiences and therefore higher life satisfaction. More positive experiences will occur because the greater access to resources, reciprocal influence, and trust associated with high-quality LMX will be related to greater need fulfillment and opportunities for mindful activity, as well as reduced job tensions (e.g., reduced role stress; Thomas \& Lankau, 2009). As argued above, age similarity will be related to higher LMX and in turn, employees with similar aged supervisors will report higher life satisfaction. Dyads with age differences not aligned to traditional age-related status norms will not develop high-quality LMX relationships, and those with age differences that do align with implicit assumptions about age and role will be more likely to progress through the three stages of LMX development. Based on this, employees with older supervisors are expected to have better LMX relationships, and therefore higher life satisfaction, than employees with younger supervisors.

The limited organizational research that exists suggests that life satisfaction is positively related to job performance (Duckworth, Quinn, \& Seligman, 2009; Jones, 2006; Shaw \& Gupta, 2001), and negatively related to job avoidance (Judge \& Locke, 1993), turnover intentions, and job burnout (Demerouti, et al, 2000; Haar \& Roche, 2010). However, despite the fact that work is a primary life domain for most people, the majority of studies investigating life satisfaction have been conducted outside of the work context. Life satisfaction has mostly been studied in other domains and is identified as an important public health construct, linked to obesity, smoking, drinking rates, and physical 
inactivity (Strine, Chapman, Balluz, Moriarty, \& Mokad, 2008). Chida and Steptoe (2008) reported meta-analytic results that the positive affect and life satisfaction components of subjective well-being were both related to reduced mortality. Also, satisfaction with life has also been associated with lower levels of sleep complaints (Brand, Beck, Hatzinger, Harbaugh, Ruch, \& Holsboer-Trachsler, 2010).

In sum, life satisfaction has important implications for individual outcomes, and early research suggests an effect on organizational outcomes as well. Erdogan and colleagues (2012) identified the "scant attention paid to the concept of life satisfaction in the management field as a critical research gap," (p. 1039), and recommended life satisfaction as an essential factor that should be studied in organizational research. The current study addressed this gap by looking at life satisfaction within an organizational context and with application of LMX theory.

\section{Retirement Intentions}

Feldman (1994) defined retirement as "exit from an organizational position or career path of considerable duration, taken by individuals after middle age, and taken with the intention of reduced psychological commitment to work thereafter," (p. 287). Note that most retirement researchers focus on voluntary retirement and consider it to be a complex and dynamic process. Retirement decision-making is commonly conceptualized as three stages. The first stage includes thinking about retirement and imagining what it would look like and feel like. These thoughts shape a person's "preference to retire". In the next stage, a person decides that they will retire soon, and they begin to make plans for when and how ("decision to retire" or retirement 
“intentions"). Finally, an individual makes the transition into retirement, what Beehr, called the "act of retirement" (Beehr, 1986; Beehr, 2014). Wang and Shi (2014) describe similar phases as the temporal process model of retirement (see also Feldman \& Beehr, 2011; Wang \& Shultz, 2010).

A great deal of research has identified economic and health factors as key components influencing the retirement decision, but psychosocial factors also play a role (Barnes-Farrell, 2003). Wang and Shi (2014) argue "individual attitudes toward retirement are probably the most proximal predictors of retirement-related behaviors" (p. 219). Moreover, Shultz and Wang (2011) further explain how a psychological perspective on retirement can contribute by helping to explain what motivates the decision-making process. Although there is great breadth of retirement research, there is not a single dominant psychological perspective or theoretical foundation informing how to explain or understand the retirement process. Some psychological theories that are used to understand and explain retirement decisionmaking include social identity theory (e.g., Feldman \& Beehr, 2011), role theory (e.g., Zaniboni, Sarchielli, \& Fraccaroli, 2010), and expectancy theory (e.g., DeVaney \& Kim, 2003).

Social identity theory (explained above; Tajfel \& Turner, 1986) is used to describe how a person's retirement decision is influenced by self-image and group membership. For example, an individual will be less likely to retire if their self-concept is closely tied to their work, and especially if the group or organizational membership enhances identity perceptions. Supervisors and employees that are part of the same age 
group are more likely to have their identity linked to that relationship and to receive positive self-image affirmations. Additionally, negative age stereotypes are known to impact retirement decisions (Wang \& Shultz, 2010) and these biases are more likely to occur in dissimilar aged dyad. Further, older employees with younger supervisors may experience or perceive a lack of respect within their organization or society as a result of status incongruence in relation to implicit assumptions. This suggests older workers with similar aged or older supervisors may have lower intentions to retire.

Role theory (Biddle, 1986) suggests that social expectations will influence retirement decisions, such that assumptions regarding appropriate timing of retirement that are held by members of one's social circle will impact a person's decision of when to retire. In other words, if an employee perceives that their supervisor expects them to retire, they are more likely to do so. Implicit career timetables will encourage perceptions that a worker of a certain age should retire, and out-group biases may cause younger supervisors to underestimate an older employee's work ability leading to increased attitudes that an older employee should retire. These attitudes will unconsciously (or consciously) pressure older employees to retire, consequently leading to greater employee intention to do so.

Finally, expectancy theory (Vroom, 1964) argues that desires to enhance pleasure and avoid pain motivate particular behaviors or courses of action. This theory suggests retirement decisions will be influenced by beliefs regarding potential outcomes of staying in a job versus retiring. Dyadic partners who share group membership are more likely to have a pleasurable experience, and thus these employees should have a greater desire to 
stay in the partnership and delay retirement than those in dissimilar dyads who may find the partnership anxiety provoking (Tajfel \& Turner, 1986). Further, older employees with a younger supervisor may experience discomfort and reduced job satisfaction as a result of status incongruence (Lawrence, 1984), and therefore directional age differences should also be associated with increased retirement intentions.

LMX should be related to retirement intentions because a positive relationship with one's supervisor will contribute to a positive work environment including positive social support, shared resources, and developmental opportunities. As a result, employees will feel less desire to leave. Employees from dyads similar in age will have more positive LMX relationships (as argued above), and therefore lower retirement intentions. When there are age differences between dyad partners, LMX will be of a lower quality when supervisors are younger than employees and this will contribute to greater intentions to retire.

Consequences of retirement occur on multiple levels. For instance, on a macrolevel, as the ratio of retirees compared to the working population declines, inadequate resources will be available for support, leading to economic strain. Loss of institutional knowledge, especially if retirement occurs en masse within organizations, is a macrolevel consequence. Micro-level, or individual outcomes, include the possible decrease of financial and psychological well-being and are associated with the transition to retirement (Szinovacz, 2003). Given the scope of consequences related to retirement and the trend of an aging population, there is a rising need to better understand the antecedents and 
outcomes associated with retirement, and to identify how organizations might retain older workers (e.g., Wang \& Shi, 2014).

As noted previously, employees within the construction industry face unique work conditions and increased health risk factors (Bodner et al., 2014; Peterson \& Zwerling, 1998). As a result, and also due to the availability of government pensions for municipal workers in this sample, older workers in this population may be especially prone to early retirement. Identifying ways to reduce retirement intentions among these employees may be particularly beneficial.

\section{Hypotheses}

The theory and empirical findings considered above inform the current study. Based on the relational demography framework, I expected that supervisor and employee age dissimilarity would be associated with decreased attraction, increased avoidance, more negative affect, and negative biases which would adversely impact the work outcomes discussed. For instance, negative affect related to out-group membership and empirical findings that age dissimilarity is related to inequitable outcomes indicate employees would have lower job satisfaction when their supervisor is in a different age group. Employees with similar aged supervisors have greater trust and more positive interactions which should relate to more opportunities for personal and professional development and lower job tensions as compared to employees from dyads with age group differences. Consequently, employees of a similar age to their supervisor will report higher life satisfaction. Expectations that retirement could lead to escape from an uncomfortable working relationship due to out-group membership will increase 
retirement intentions, and desire to promote and maintain positive self-identity through in-group membership will reduce retirement intentions. Therefore, retirement intentions will be lower for employees within the same age group as their supervisor. Finally, the social exchanges required for high-quality LMX are less likely to occur among dissimilar dyads due to negative biases of dissimilar partners including lack of respect and trust.

Hypothesis 1: Supervisor/employee age dissimilarity (nondirectional age differences) will be negatively related to a) job satisfaction, and b) life satisfaction, and will be positively related to c) retirement intentions. Additionally, dyad age dissimilarity will be negatively related to d) LMX. Further, violation of implicit assumptions about career timelines and ideal leader/employee characteristics suggest that supervisor and employee directional age differences will impact the work outcomes discussed. The theories and empirical research presented above, such as negative ratings of younger supervisors by older employees (Collins et al., 2009) and fewer development opportunities offered to older workers by younger supervisors (Shore et al., 2003) suggest employees within dyads that are age and status incongruent will have lower job satisfaction and life satisfaction than employees in dyads that are age and status congruent. Age-related status incongruence may also cause older workers to perceive a lack of respect from members of the organization and community and therefore could struggle to enhance a positive identity through their work. Because of this, older employees with younger supervisors will want to exit the role, and thus will be more likely to report intentions to retire than employees with older supervisors or the same age supervisor. LMX quality is also likely to be lower for status 
incongruent dyads because implicit leadership and performance theories, as well as negative biases associated with deviation from the implicit career timeline indicate to dyad partners that exchange will not be of mutual benefit.

Hypothesis 2: Status incongruence (directional age differences) within dyads will be negatively related to a) job satisfaction, and b) life satisfaction, and will be positively related to c) retirement intentions. Additionally, status incongruence will be negatively related to d) LMX.

Leaders play a critical role in shaping employees' work experiences, and empirically LMX is related to numerous employee attitudes and behaviors. Therefore, I expect that LMX will also be related to life satisfaction and retirement intentions. For instance, high-quality relationships are likely to improve life satisfaction through greater attainment of needs, opportunities for personal and professional development, and low job tensions including access to important resources. High quality LMX relationships could reduce retirement intentions by creating an enriching work experience and through opportunity to derive positive self-identity. Additionally, the mutual obligation component of LMX may cause an older worker to perceive that remaining on the job is expected and desired. Low-quality LMX relationships are less likely to foster interactions that meet employee needs and may be associated with greater conflict and job tensions. Therefore LMX should be negatively associated with life satisfaction and positively associated with retirement intentions. Although studies have demonstrated a relation between LMX and job satisfaction over time (e.g., Volmer, Niessen, Spurk, Linz, and Abele, 2011), it was included here for replication with a six-month time lag. 
Hypothesis 3: LMX at Time 1 will be positively related to Time 2 a) job satisfaction, and b) life satisfaction, and negatively related to Time 2 c) retirement intentions.

Building from these first three hypotheses, dyads similar in age, or those with age differences that align with age-related status norms, should have better LMX relationships, and in turn, these higher quality relationships will lead to higher reports of job satisfaction and life satisfaction, and greater intention to remain at work. This will occur through an increase in positive and motivating job characteristics such as increased autonomy, increased satisfaction of needs (including interpersonal needs), and stronger feelings of obligation toward one's supervisor. Looking at it another way, age dissimilarity and status incongruence will hinder LMX relationship development, and consequently employees within these dyads will experience lower job satisfaction and life satisfaction, and increased retirement intentions. For instance, these employees are more likely to be micromanaged, derive less meaning from their work, and will be more likely to find ways of enhancing their identity outside of work. It is expected that LMX is a key component explaining how supervisor/employee age differences impact workrelated outcomes.

Hypothesis 4: LMX at Time 1 will partially mediate the relationship between supervisor and employee age differences and Time 2 outcomes: a) job satisfaction, b) life satisfaction, and c) retirement intentions.

See Figure 3 for an illustration of the hypothesized model.

\section{Method}




\section{Participants}

Participants were construction workers from two municipal works agencies in the Pacific Northwest. Employees within each team reported to one direct supervisor, and team size ranged from 6 to 20 members. Job titles include utility worker, water operations mechanic, electrician, plumber, carpenter, and construction equipment operator. The original sample included 461 employees and supervisors from 38 workgroups. Nine of the workgroups had changes in leadership between Time 1 and Time 2, and 6 supervisors did not report their age. The 15 workgroups thus affected were not included in analyses. Additionally, 3 employees were promoted as part of the change in leadership, and 1 employee reported a clearly false age (86); these participants were also excluded from analyses. The final sample was comprised of 419 employees from 23 work groups. Teams (Organization A: $k=13, n=245$; Organization B: $k=10, n=174$ ) have responsibilities including sewer repair, sidewalk maintenance, and construction maintenance. Employee ages range from 19 to 72 years old $(M=44.37, S D=9.76)$; supervisor ages range from 38 to 64 years old $(M=49.78, S D=7.22)$. Directional age differences ranged from -20.5 to 45.0 with negative values indicating cases when the supervisor is younger than the employee (status incongruent) and positive values indicating the supervisor is older than the employee $(M=6.4, S D=11.64)$. Twenty-three percent of employees were about the same age as their supervisor (less than 5 year age difference), $57.6 \%$ of supervisors were older than their employees by more than 5 years, and $19.3 \%$ of supervisors were younger than their employees by more than 5 years. The greatest age difference was between a 19 year old employee and his 64 year old 
supervisor. The sample is predominantly White $(80 \%$ of employees and $79 \%$ of supervisors) and male ( $80 \%$ of employees and supervisors). Thirty-six percent of employees have been with their organizations less than five years, $28 \%$ between $5-9$ years, $25 \%$ between $10-20$ years, and $11 \%$ more than 20 years. For supervisors, $45 \%$ have been with their organization more than 20 years, and none less than 5 years $(5-10$ years: $36 \%, 11-20$ years: $18 \%)$.

For the outcomes related to retirement intentions, different age subsets of the population were explored starting at 40 years of age and older $(n=123)$, and also 45 years of age and older $(n=89)$, as well as 50 years of age and older $(n=59)$. In a recent review, Truxillo, Cadiz, and Hammer (2015) conceptualized an "older worker" as someone near to, or past retirement age. They noted that social norms and retirement eligibility varies greatly between different countries, cultures, and job types, and they recommended that in the U.S., those in their late 50 s and 60 s could be considered as approaching retirement. However, Shultz and Wang (2011) suggest that some workers are choosing to retire as early as their 40 s due to shifting trends indicating early retirement from one's career (with the possibility of beginning a new one). Moreover, Feldman (1994) defines retirement as beginning in middle age, which could be considered to start at the midpoint of one's life. As of 2011, the U.S. average life expectancy was 78.7 years old ( 76 for men and 81 for women; Organization for Economic Cooperation and Development, 2013), making the midpoint 39 years old. Furthermore, this specific population is eligible for retirement benefits 30 years after the date of hire. If an employee began with the organization after graduating high school at 
the age of 18 , retirement would be a realistic possibility at the age of 48 . Based on this, as well as the substantial loss of power when the subsample cut off is 45 years of age or older, the $40+$ subset will be the focus of the results reported here. Note that results conducted with samples aged 45 and older and 50 and older did not differ in significance from the results for the subset comprised of employees 40 years of age and older.

\section{Procedure and Design}

The data for this project were obtained as part of a larger data collection effort supported by the Oregon Healthy Workforce Center (OHWC) and the National Institute of Occupational Safety and Health (NIOSH; grant U19OH010154). Paper-and-pencil surveys were administered to assess a randomly controlled trial intervention, the Safety and Health Improvement Program (SHIP). SHIP is a project aimed at improving worker safety and health through leadership training on work-family and safety supportive behaviors, as well as through improving team effectiveness processes. Intervention results are not the focus of this study, therefore data from both treatment and control groups will be used, and experimental condition will be controlled for in hypothesis tests.

Surveys took about 30-45 minutes for participants to complete and were administered at work, on company time, and by trained research assistants. $\$ 25$ gift cards were provided as incentive to those who opted to participate. Data for this study were taken from two post-intervention time points with a six-month lag between measurement occasions. This allowed for the existing dyad age differences to be antecedents; LMX to be a mediator measured at the first time point; and job satisfaction, life satisfaction, and retirement intentions, measured six months later, to be the outcomes. 


\section{Measures}

Employee and supervisor age. Participant chronological age (in years) was reported in the survey. Time 1 age was used. However, if age was missing at Time 1 and available at one of the other survey time points, these were used. When age was available at both alternate time points, the higher age was used.

Leader-member exchange (LMX). Upon reviewing and testing multiple measures of LMX, Graen and Uhl-Bien (1995) concluded that the 7-item scale (LMX7; Scandura \& Graen, 1984, $\alpha=.84-.86$ ) measuring employee perceptions of leader support, recognition, and working relationship; level of the supervisor's understanding of job problems and needs; and employee loyalty to, and confidence in, the supervisor, is the most appropriate and recommended measure. In line with these conclusions, the LMX7 was used to measure employee perceptions of leader-member exchange quality. As expected, in the present study this measure demonstrated good internal consistency $(\alpha=$ .92). Participants responded on a 5-point scale to items such as, "I have enough confidence in my supervisor that I would defend and justify his/her decision if he/she were not present to do so." See Table 1 for a full list of the items and response options.

Job satisfaction. Global job satisfaction was measured using three items adapted from the Michigan Organizational Assessment Questionnaire-Job Satisfaction Subscale (MAOQ-JSS; Cammann, Fichman, Jenkins, \& Klesh, 1983). Bowling and Hammond (2008) conducted a meta-analysis demonstrating psychometric support for use of this measure and pointed out that the MAOQ-JSS has a distinct advantage over other job satisfaction measures (specifically JDI; Smith et al., 1969). A sample item is, "In general, 
you like working at your job." Employees were asked to indicate their level of agreement, from "Strongly Disagree" to "Strongly Agree", on a 5-point scale. Although the MAOQ originally used a 7-point response scale, other researchers have reliably used a 5-point version (Allen, 2001, $\alpha=.88$; Grandey, 2003, $\alpha=.89$ ). Measurement reliability with this version was demonstrated among these participants as well $(\alpha=.85)$. The complete list of items can be seen in Table 1.

Life satisfaction. The Satisfaction with Life Scale (SWLS; Diener et al., 1985, $\alpha$ $=.87)$ was used to assess employee life satisfaction. This measure includes five questions and has been recommended for its strengths in assessing an "individuals' conscious evaluative judgment of his or her life by using the person's own criteria (Erdogan et al., 2012; Pavot \& Diener, 1993, p. 164). It was a reliable measure among participants in the current study $(\alpha=.90)$. Employees were asked to indicate their level of agreement from 1 ("Strongly Disagree") to 5 ("Strongly Agree") on items such as, "The conditions of my life are excellent." The scale can be viewed in its entirety in Table 1.

Retirement intentions. It has been argued that people perceive little control over actual retirement decisions indicating that psychosocial predictor variables are best matched with attitudes about retirement (Topa, Moriano, Depolo, Alcover, \& Morales, 2009). The items used here were adapted from Hom, Griffeth, and Sellaro's (1984) intention to quit $(\alpha=.87)$ and thoughts about quitting $(\alpha=.75)$ scales. The adapted measures demonstrated acceptable reliability $(\alpha=.84)$ in the current sample. An item from this scale is, "If I had my own way, I would retire soon." Participants again 
indicated their level of agreement from "Strongly Disagree" to "Strongly Agree", on a 5point scale. All three items can be reviewed in Table 1.

Control variables. First, because intervention effects are not of interest in this study, intervention condition was controlled for in all analyses. Second, because two organizations are being treated as one sample, variance explained by organizational membership was also controlled for in all analyses. Intervention condition and organizational membership were coded as 0 or 1 (control/intervention; organization A/organization B) and entered by research assistants according to a key that matched participant ID to these conditions. Third, tenure (self-reported in years, Time 2) is significantly correlated with life satisfaction and retirement intentions in this sample and was explored as an additional control variable for hypotheses relating to these outcomes. Fourth, a one-item self-report of general health (Time 2) was examined as a possible control for hypotheses that included life satisfaction and retirement intentions as an outcome. Health has been identified as a leading indicator of retirement decisions in past research (e.g., Barnes-Farrell, 2003) and is also related to one's satisfaction with life (e.g., Palmore \& Luikart, 1972). The health measure comes from the SF-12 (Ware, Kosinski, \& Keller, 1996) and asks, "In general, would you say your health is:” with response options ranging from "Poor" to "Excellent" on a 5-point scale. Finally, binary measures of gender differences (male/female) were also investigated as a control variable

\section{Analyses}

Preliminary analyses. The data were examined to look for any unusual item values such as values that were not within the response range. Residual plots were 
examined to assess assumptions about normality of data. These, along with skew values within the acceptable range, support this assumption. Box plots and stem-and-leaf plots indicated one outlier for LMX and 10 outliers for job satisfaction, however these values were within the expected range and thus retained. One employee participant who reported an age of 86 was removed because it is known that no employees were this age based on experience working with the employees throughout the intervention.

Inspection of the scree plots and eigenvalues for each scale confirmed the measures were assessing one underlying construct. This was as expected given the LMX, job satisfaction, and life satisfaction measures are well established, however the retirement intentions scale was adapted from previous measures. The three retirement items load onto one factor explaining $76.8 \%$ of the variance in retirement intentions. As reported above, and also in Tables 1 and 2, tests of reliability using Cronbach's Alpha were all well above the acceptable .70 cutoff.

\section{Cross-level polynomial regressions and response surface methodology. Cross-}

level polynomial regression analysis and response surface methodology were used to test the first two hypotheses relating to nondirectional and directional age differences. This method has many advantages over difference scores used in past research, and is a now a commonly applied approach for assessing the effect of two variables congruence/incongruence on a third variable. The polynomial regression equation allows for each component to be included in the analyses, as opposed to reducing two dimensions (employee age and supervisor age) to one (difference). Polynomial regression analysis eliminates many of the issues associated with difference scores including 
reduced reliability of the difference score measure (as compared to component measures), confounded effects, and untested constraints. This alternative to difference scores, as fully described by Edwards (2002), allows for examination of complexities relating to congruence and incongruence that cannot be asked or answered with difference scores. The method was expanded for use with multilevel data by Jansen and Kristoff-Brown (2005).

Three assumptions of polynomial regression analysis were all satisfied. These include commensurate component measures (employee and supervisor age reflect the same construct), measures are at interval (or ratio) level, and measures are on the same numeric scale. First, employee and supervisor ages were centered in order to aid interpretation and to reduce multicollinearity (Edwards \& Parry, 1993). To maintain scale equivalence, the pooled grand mean value of age was subtracted from both employee and supervisor age scores. Next, to examine if nondirectional (incongruent) or directional (congruent) age differences influenced the Time 1 and Time 2 outcomes, employee age (E), supervisor age $(S)$, employee age squared $\left(E^{2}\right)$, the product of employee age and supervisor age $\left(E^{*} S\right)$, and supervisor age squared $\left(S^{2}\right)$ were regressed on a) job satisfaction, b) life satisfaction, c) retirement intentions, and d) LMX. With Z representing the outcome of interest, the polynomial regression equation is: $\mathrm{Z}=b_{0}+b_{1} \mathrm{E}$ $+b_{2} \mathrm{~S}+b_{3} \mathrm{E}^{2}+b_{4} \mathrm{E}^{*} S+b_{5} \mathrm{~S}^{2}$

Analyses were conducted using PROC MIXED in SAS with syntax adapted from Jansen and Kristoff-Brown (2005). PROC MIXED allows the nesting of individuals within work groups to be accounted for, and estimation of random effects. This is 
particularly important for LMX because the intraclass correlation (ICC) is greater than .1 $(\mathrm{ICC}=.12)$ indicating group dependency, or in other words that group membership is related to LMX scores. ICCs for the Time 2 outcomes were all less than .1. However given the structure of the data (nested) and nature of the questions being posed (supervisor dependent), it is still appropriate to account for work group membership and thus PROC MIXED was also used to examine the job satisfaction, life satisfaction, and retirement intentions outcomes. Intercepts, $E$ and $E^{2}$ were estimated as random effects. Although it could be argued that $\mathrm{E}^{*} \mathrm{~S}$ should also be treated as a Level-1 random effect, this was excluded to minimize the number of parameters being estimated with consideration of individual and group sample sizes.

It is generally recognized that polynomial regressions can be difficult to interpret, and thus response surface methodology (RSM; Box \& Draper, 1987) is recommended as a complementary analysis method (Edwards, 2002; Jansen \& Kristoff-Brown, 2005). RSM provides a way to visualize the three-dimensional relationship and to test significance of the linear (first-order) and curvilinear (second-order) relationships of congruence $(E=S)$ and incongruence $(E=-S)$. Coefficients from the polynomial regression were used to graph the response surface with a template freely available from Edwards' website (http://public.kenan-flagler.unc.edu/faculty/edwardsj/), and the significance of first-order and second-order response surface features were assessed by testing the linear combinations using CONTRAST statements in SAS.

Multilevel regression. Multilevel regression using PROC MIXED in SAS was applied to test Hypothesis 3. Specifically, Time 2 job satisfaction, life satisfaction, and 
retirement intentions were regressed on Time $1 \mathrm{LMX}$ in three separate analyses. As noted earlier, PROC MIXED is used to account for the nesting of individuals within work groups. Intercepts, employee age, and employee age squared were allowed to vary (Level 1 random effects).

Mediation analysis. The block variable approach was planned for testing the mediation effects proposed in Hypothesis 4. This method is recommended by Edwards and Cable (2009) for assessing the direct and indirect effects of (in)congruence models. In brief, the coefficients from a polynomial regression are used to compute a new variable that is a weighted linear composite, with the estimated polynomial regression coefficients serving as the weights. The resulting "block" variable represents the combined effect of the five quadratic terms. Edwards and Cable note, "the variance explained by the equation using the block variable is identical to that explained by the equation using the original quadratic terms, given that the block variable is computed from the coefficient estimates for the quadratic terms themselves" $(2009$, p. 660). This method was unnecessary as results from polynomial regressions indicated mediation analyses were not warranted. Post hoc mediation tests were conducted using Sobel's method.

\section{Results}

This section will begin with the presentation of preliminary analyses and consideration of statistical controls. Next, the results from the polynomial regression analysis and RSM relating to non-directional and directional age differences (Hypotheses 1 and 2) will be discussed for each outcome. The effects of Time 1 LMX on each Time 2 
outcome will then be reported (Hypothesis 3). As noted above, tests to assess Hypothesis 4 were not warranted. Finally, post hoc analyses and results will be presented.

\section{Preliminary Analyses and Controls}

Descriptive statistics, correlations, and reliability coefficients can be seen in Table

2. Job satisfaction is higher in Organization A $(r=.12, p<.05)$, and intervention condition is marginally related to $\operatorname{LMX}(r=-.09, \mathrm{p}<.10)$, such that LMX is lower for those who participated in the intervention. As discussed previously, these conditions were controlled for in all analyses; models without these variables were also investigated, and significance of results were the same.

Those who reported better health also reported higher life satisfaction $(r=.34, p<$ $.01)$. General health was retained as a statistical control for analyses relating to life satisfaction, and analyses were run with and without this control variable. Results did not differ based on inclusion of this control; results with health included as a control are reported.

Tenure was negatively related to life satisfaction $(r=-.17, p<.05)$ and positively related to retirement intentions $(r=.29, p<.01)$ in this sample. Analyses with these outcomes were run with and without tenure and results did not differ. Reported results are from analyses that do not include tenure as a control. This decision was made because tenure is highly correlated with employee age $(r=.48, p=.01)$ indicating that there is considerable overlap in the variance being explained by these two variables. Additionally, due to missing data, the inclusion of tenure results in a large reduction of sample size, and therefore a great loss of power. Gender was not significantly correlated 
with any outcome variables and therefore was not included as a statistical control for any analyses.

\section{Hypothesis Testing}

Age (in)congruence effects. Hypothesis 1 states that regardless of the direction of age differences, as the difference between employee and supervisor age increases, a) job satisfaction and b) life satisfaction will decrease, and c) retirement intentions will increase. Additionally, dyad age similarity will be positively related to d) LMX. Given the complexity of the analytical approach, it is useful first to consider what the results would look like in terms of model parameters and graphs if the hypothesized effects were supported. If outcomes are positively impacted by age congruence, the coefficients for both $\mathrm{E}$ and $\mathrm{S}$ will be significant, and the response surface will look like the example presented in Figure 4. Notice the peak is along the line of congruence $(\mathrm{E}=\mathrm{S})$ indicating the outcome is maximized when employee and supervisor age are equal, and that the line is flat, illustrating the outcome is maximized along this line regardless of the age value. Second, the line of incongruence $(E=-S)$ has a symmetric downward curvature representing a decrease in the outcome as age differences increase in either direction. This figure depicts the response surface hypothesized for nondirectional age differences in relation to job satisfaction, life satisfaction, and LMX. Retirement intentions are hypothesized to hold the same shape, but reversed, such that the line of congruence will represent the point at which retirement intentions are lowest, and the line of incongruence would symmetrically curve upward. Quantitatively, a non-significant slope $\left(b_{1}+b_{2}\right)$ and curvature $\left(b_{3}+b_{4}+b_{5}\right)$ of $\mathrm{E}=\mathrm{S}$, combined with a significant $\mathrm{E}=-\mathrm{S}$ curvature $\left(b_{3}-b_{4}+\right.$ 
$b_{5}$ ), will support the hypotheses for all outcomes, with a negative curvature of $E=-S$ supporting H1a, H1b, and H1d and a positive curvature supporting H1c.

Hypothesis 2 states that the direction of age differences will matter such that incongruence will be negatively related to a) job satisfaction, b) life satisfaction, and d) LMX, and will be positively related to c) retirement intentions. Recall that a significant curvature of the incongruence line $(E=-S)$ was expected to support a congruence effect such that the effect was the same regardless of the direction of age difference, thereby creating a symmetric curve on both sides of $E=S$ (Figure 4). To support an incongruence effect, it is expected that the relationship between age differences and the outcomes will be linear such that as age differences increase, the effect will differ depending on the direction one moves along $\mathrm{E}=-\mathrm{S}$ away from $\mathrm{E}=\mathrm{S}$. For example, $\mathrm{LMX}$, job satisfaction, and life satisfaction are expected to be higher when the supervisor is older than the employee, as compared to when the supervisor is younger than the employee, and thus we expect these outcomes to be higher within the front, left quadrant of the graph as compared to the right, back quadrant. Support for this hypothesis is obtained with a significant positive slope of $\mathrm{E}=-\mathrm{S}$ for LMX, job satisfaction, and life satisfaction. The opposite effect is hypothesized for retirement intentions and thus a significant negative slope is expected for that outcome. As with the congruence analyses, both E and S must be significant to support hypotheses about an incongruence effect.

Quantitative results can be viewed in Table 3 and response surfaces are illustrated in Figures 5-8. First, significant coefficients of both $\mathrm{E}$ and $\mathrm{S}$ are not obtained for any of 
the outcomes. Therefore, Hypotheses 1a-d and Hypotheses 2a-d must be rejected. However, examination of the response surfaces provides additional information.

It can be seen in Figure 5 that the three-dimensional relationship between employee and supervisor age with LMX does not mimic the hypothesized effect illustrated in Figure 4. Rather than a flat peak along $E=S$, a significant slope exists along the line of congruence $\left(b_{1}+b_{2}=-.08, \mathrm{p}<.001\right)$. This reveals that when employees and supervisors are the same age, LMX is significantly higher when both are younger and lower when both are older. Additionally, a significant linear slope $\left(b_{1}+b_{2}=.06, p<.01\right)$ for the line of incongruence $(E=-S)$ in relation to LMX suggests that the direction of age differences do matter, however the direction of the relationship is opposite what was expected. This positive slope shown in Figure 5 demonstrates that LMX is lowest when the supervisor is considerably older than the employee (front, left quadrant), and that LMX increases as employee age increases toward supervisor age and continues to increase as employee age exceeds supervisor age (back, right quadrant). In other words, results reveal that as age differences increase, LMX increases when the supervisor is younger than the employee, but when age differences increase and the supervisor is older than the employee, LMX decreases. As noted previously, employee age (employee age: $b$ $=-.01, p=.41$ ) and supervisor age (supervisor age: $b=-.07, p<.001$ ) do not both significantly relate to LMX. Only a significant main effect of supervisor age on LMX is indicated. This can be seen in Figure 5 as a consistent trend across employee ages, with LMX higher when supervisors are younger and lower when supervisors are older (right 
side of graph compared to left side). This is explored further with post hoc analyses (below).

Response surface analyses for job satisfaction, life satisfaction, and retirement intentions did not reveal any significant joint first-order $\left(b_{1}+b_{2}, b_{1}-b_{2}\right)$ or second-order effects $\left(b_{3}+b_{4}+b_{5}, b_{3}-b_{4}+b_{5}\right)$. Visual inspection of Figure 6 suggests job satisfaction increases as age differences increase, with a greater increase when supervisors are younger than the employee.

Figure 7 illustrates a slight trend toward decreased life satisfaction when employees are older and their supervisor is younger, with increased life satisfaction when the employee is younger and supervisor is older, however these relationships are not significant and the response surface is quite flat. As illustrated on the graph, it is interesting to note there is a significant negative correlation between employee age and life satisfaction $(r=-.19, p<.05)$, and this trend reverses for supervisors, however this correlation is non-significant $(r=.07, p>.10)$.

Finally, the response surface with retirement intentions as the outcome (Figure 8) suggests that intentions to retire are greatest for employees of mean age with similar aged supervisors, and that retirement intentions decrease as age differences increase in either direction, with a stronger decrease when the supervisor is older than the employee. This trend follows the relationship proposed in Hypotheses 1c and $2 \mathrm{c}$ but again the results were not significant. It should be noted that the individual and group sample sizes might not have been sufficient to find significant results with the number of parameters estimated. Figure 8 also depicts that when employee and supervisors are the same age, 
retirement intentions are lowest when both are younger. It could be argued that this is an age effect, however age and retirement intentions are not significantly correlated in the subset sample $(r .11, p>.10)$. The trends discussed for each outcome will be given additional consideration in the discussion section.

LMX and Time 2 outcomes. Hypothesis 3 stated that LMX at Time 1 would be positively related to Time 2 a) job satisfaction and b) life satisfaction, and negatively related to Time $2 \mathrm{c}$ ) retirement intentions. Multilevel regression results revealed support only for $\mathrm{H} 3 \mathrm{a}$. As expected based on previous research, job satisfaction was predicted by LMX $(b=.38, p<.001)$. Results did not demonstrate a significant relationship between LMX and life satisfaction $(b=.10, p=.15)$ or retirement intentions $(b=-.08, p=.30)$.

Mediation. It was proposed that Time 1 LMX would mediate the relationship between age (in)congruence and Time 2 outcomes. There were no significant effects between age (in)congruence and LMX, and also no significant effects between age (in)congruence and job satisfaction, life satisfaction, or retirement intentions. Without significant relationships between independent variables and other model variables, mediation analyses were not necessary to conclude Hypotheses 4a-d are not supported.

\section{Post Hoc Analyses and Results}

Multilevel regression analysis was conducted to confirm the main the effect of supervisor age on LMX that was indicated by the polynomial regression results. Supervisor age significantly and negatively related to $\operatorname{LMX}(b=-.05, p<.001)$. When workgroup supervisors were younger (on a spectrum of younger to older), better quality LMX was reported by employees in this sample. 
These results linking supervisor age and LMX in combination with results linking LMX and job satisfaction suggest the possibility of a significant indirect effect. There is debate among statisticians about the appropriate methodology for assessing this type of effect. Based on the Baron and Kenny (1986) causal steps approach to mediation, if the predictor variable is not significantly related to the outcome variable, there is no effect to be mediated. Supervisor age was not significantly related to job satisfaction $(b=-.01, p=$ $.47)$ and therefore from this perspective no mediation existed.

However recently statistical experts have argued that this approach is flawed. Hayes (2013) argues that the best way to test for mediation is not through a series of tests as is used with the casual steps method, but rather with a single inferential test of the indirect effect. Hayes explains that it is possible for a predictor variable to influence an outcome variable via a mediator variable, even if the relationship between the predictor and outcome is not significant. From this perspective, an indirect effect is possible. A significant indirect effect of supervisor age on Time 2 job satisfaction through Time 1 LMX was indicated by Sobel's test $(z=-3.88, p<.001)$. In other words, employee-rated LMX was higher when supervisors were younger, and in turn job satisfaction was also higher. The author invites readers to interpret these results according to their own perspectives about calculating indirect effects.

\section{Discussion}

As organizational age heterogeneity increases, researchers and practitioners seek to better understand the effects of a multigenerational workforce, teams, and dyads. In line with this, the current study used a time-lagged design to investigate the effect of 
employee and supervisor age (in)congruence in relation to job satisfaction, life satisfaction, and retirement intentions, all mediated by leader-member exchange (LMX) quality. Results did not support any of the proposed hypotheses, with the exception of the established relationship between LMX and job satisfaction. However, response surface graphs and polynomial regression results directed post hoc analyses which did reveal a main effect of supervisor age on LMX and an indirect effect of supervisor age on job satisfaction (Time 2) through LMX (Time 1). Employees in this sample reported higher quality LMX when supervisors were younger, regardless of employee age, and in turn employees with younger supervisors reported higher job satisfaction. These results will be discussed, and the trends illustrated with response surface graphs will be used to direct discussion including implications and future directions.

Hypotheses 1 and 2 sought to identify the effects of employee and supervisor age differences from two different theoretical frameworks with the aim of clarifying inconsistent results and adding unique value. This study also contributes to these literatures by acknowledging criticisms about past analytical methods used to investigate age difference effects (difference scores; e.g., Edwards, 2002) and introduced the use of cross-level polynomial regression and response surface methodology to examine this phenomenon.

\section{Age Differences}

First, the relational demography literature demonstrates that similarity is associated with greater liking and increased in-group bias (e.g., Byrne, 1971), and based on this it was suggested that similarity would be associated with a better quality leader- 
member exchange (LMX), and in turn higher job and life satisfaction and lower retirement intentions. Current research has demonstrated inconsistent findings relating age differences with job satisfaction and LMX (Epitropaki \& Martin, 1999; Pelled \& Xin, 2000; Schaffer \& Riordian, 2013; Shore et al., 2003), and no known research has examined employee and supervisor age differences in relation to life satisfaction or retirement intentions. Age similarity was not significantly related to any of the outcomes in this study and therefore support was not obtained for this framework with these constructs and population. Harrison and colleagues (2002) argue that over time, deeplevel characteristics such as attitudes, values, and beliefs have a stronger relationship to intergroup outcomes than surface-level characteristics such as demographics. Although age is generally considered a surface-level trait, it was suggested that because age is associated with shared historical experiences, it could potentially act as a deep-level trait impacting group membership and interactions. This does not appear to be the case based on these results. Findings from this study add support to the research indicating age alone is not an important enough factor to influence work processes and work-related attitudes (e.g., Thatcher \& Patel, 2011).

Second, from an implicit social role perspective (e.g., Lawrence, 1988; Lord \& Maher, 1991) the directional component of supervisor and employee age differences was predicted to be an additional component for understanding how age differences impact work-related outcomes by identifying a boundary condition of when age differences matter. Research examining effects related to the direction of age differences has been called for but has been rarely investigated (for exceptions see, Collins et al., 2009; Shore 
et al., 2003; Vecchio, 1993). The current study answered this call, however support for this framework was not obtained. Not only were incongruence effects non-significant, but also contrary to theoretical arguments that proposed work outcomes would be better when the supervisor was older, a main effect of supervisor age was found in the opposite direction. On average, employees reported significantly higher LMX when supervisors were younger (younger here refers to a scale of young to old, and not in comparison to employee). Previous research demonstrates that stereotypes about which age should hold certain types of jobs are malleable, shifting over time according to several factors including which particular age group is currently most represented within a particular job, job-type, or even industry (Gordon \& Arvey, 1986; Perry 1993). The results of this study support suggestions that implicit assumptions (or stereotypes) about age and work role are possibly shifting (Truxillo, Finkelstein et al., 2015). Additionally, different expectations for leaders of different ages (prescriptive stereotypes) are potentially biasing interpretations of leader behavior (Tsui et al., 19..;Zacher, Rosing, Henning, \& Frese, 2011). This will be expanded on below when results from post hoc analyses are discussed.

Together, the results of Hypothesis 1 and 2 suggest that supervisor and employee age do not interact to affect work outcomes. The methodology used in this study allows for further examination of these relationships through visualization of response surface trends. Although age (in)congruence effects were not significant, the trends depicted in the response surfaces provide interesting information and suggest possibilities for future 
research. Trends will be discussed for each outcome and the main effect of supervisor age on LMX will also be considered further.

\section{Job Satisfaction}

Although job satisfaction was not significantly related to age (in)congruence, the trend depicted by the response surface (Figure 6) suggests employee job satisfaction is higher when employees and supervisors are different ages, and highest when supervisors are younger than employees. The trends depicted are contrary to what was expected based on relational demography and implicit social role theories, however considering these frameworks together illuminates a potential explanation. It has already been discussed that age does not appear to have deep-level effects at work, and thus those with the same age group membership will seek other characteristics for differentiation (Harrison et al., 2002; Tajfel \& Turner, 1986). When employees are the same age, it is possible that organizational role becomes a more salient dimension for social comparison because of implicit assumptions associated with age and social role (e.g., Lawrence, 1988; Lord \& Maher, 1991). Employees with similar aged supervisors are more likely to experience feelings of falling behind and low comparative status. As a result these employees report lower job satisfaction (Lawrence, 1984). When age differences exist between supervisors and employees the status difference is likely explained and justified by other factors and therefore age differences do not have an impact on assessments of job satisfaction.

Recall that contradictory findings relating nondirectional age differences with job satisfaction have been previously reported in the literature (Epitropaki \& Martin, 1999; 
Shore et al., 2003). The effects of the current study, suggested by visual review of the response surface, indicate that additional exploration of directional age differences could illuminate a potential leverage point for improving employee job satisfaction. Given the small sample size compared to the number of parameters estimated, and incongruence effects that approached significance, it is possible significant results would be revealed with a larger sample.

\section{Life Satisfaction}

Results for employee and supervisor age in(congruence) on life satisfaction were not significant. The response surface depicting this relationship (Figure 7) is fairly flat, however it is interesting to note that employee age is negatively related to life satisfaction, whereas the slope illustrating the relationship between supervisor age and life satisfaction is positive. One might infer that having higher organizational status attenuates the negative relationship between age and life satisfaction, however the correlation is not significant and therefore conclusions should not be drawn from this image. Age differences were expected to impact life satisfaction through influence on other work related antecedents and mediators. As mentioned previously, research investigating life satisfaction and work is limited. The results of this study suggest the need to obtain a greater understanding of how proximal factors, such as job related tensions and quality of work life (Erdogan et al., 2012), relate to life satisfaction before examining more distal predictors such as age (in)congruence.

\section{Retirement Intentions}


As with other outcomes in this study, retirement intentions were not significantly related to age (in)congruence. The response surface (Figure 8) suggests that retirement intentions are highest when employees and supervisors are the same age, and around average age of the subsample. As age differences increase, retirement intentions decrease.

As discussed above, it is possible that employees with similar aged supervisors are more likely to perceive they are falling behind according to the implicit career timeline (Lawrence, 1984, 1988). This may be particularly true around middle age when expectations associated with implicit social role assumptions suggest middle-aged employees should be obtaining organizational roles with higher status. Middle-aged employees with similar aged supervisors may perceive they missed the opportunity to obtain higher status through organizational promotion leading to expectations that they never will (Biddle, 1986; Lawrence, 1988). This expectation and the inability to derive positive social identity because of low comparative status may motivate intentions to retire as soon as possible (Tajfel \& Turner, 1986; Vroom, 1964). However, when age differences exist employees may attribute status differences to other individual qualities such as experience or leadership ability (Tsui et al., 1989).

The low retirement intentions of older workers with younger supervisors, (illustrated in the back, right quadrant of Figure 8), is contrary to hypothesized effects, and it is interesting to note that a curvilinear relationship between supervisor age and employee retirement intentions approached significance $(p=.06)$. Pairing older workers with younger supervisors appears to be a potential leverage point to retain older employees, at least in this particular context. The trends illustrated in response surface 
graphs contribute to the current retirement literature by directing future research that could inform potential strategies for reducing retirement intentions. However, it is important to remember this discussion is based on response surface trends and not on any significant findings (hypotheses were not supported). Additional empirical research is needed to support these interpretations.

\section{LMX}

As noted above, an interactive effect of employee and supervisor age was not found to influence LMX, however employee-rated LMX was found to be significantly higher when supervisors were younger, in general (Figure 5). One might explain this finding by highlighting the physical nature of the jobs for this sample (construction workers). Indeed, qualitative data gained from discussions with organizational insiders suggests that younger attitudes and abilities are valued within this sample, and older workers are perceived to be holding on to "old" ways of doing things. A conversation had with an administrative employee at one of the organizations suggested that common stereotypes about older workers affected other employee and supervisor attitudes. The interviewed individual reported his opinion that older workers were perceived to be hindering forward-thinking progress and had trouble with technology. His perception was that the organization was eager to be "out with the old and in with the new." If these opinions are representative of commonly held attitudes by others within the organization, it may explain why employees rated LMX as lower with older supervisors in general. If these supervisors are not valued by the organization, LMX relationships would not be perceived as offering value to employees and therefore cannot be expected to be 
developed (Graen \& Uhl-Bien, 1995). On the other hand, this raises a separate issue of whether these perceptions of older and younger people within the organization are accurate, or merely fall into well-established negative stereotypes about older workers. Another explanation is provided by Zacher and colleagues (2011) who reported LMX mediated negative relationships between leader age with employee perceptions of leader effectiveness, follower satisfaction with leader, and follower extra effort, but only when leaders were rated as low in generativity. When leaders were high in generativity, the relationships between leader age, LMX, and these outcomes were not significant. Generativity did not moderate these relationships for younger leaders. In other words, older leaders who were generative were perceived more positively than those who were not, whereas leader generativity did not seem to affect the perceptions of younger leaders. This research suggests implicit assumptions that older supervisors should be generative means older supervisors are being judged mare harshly according to criteria that only applies to them. Negative attitudes about older workers within this sample may hinder older supervisors' willingness and ability to be generative resulting in lower rating of LMX.

Furthermore, one justification for younger supervisors being in a position "ahead" of others in their age groups can result in justifications that the are exceptionally skilled or qualified (Tsui et al., 1989). This means younger supervisors may be judged more positively just for being young and in a supervisor role so early in their career timetable (Lawrence, 1988). These implicit expectations and justifications indicate that even if supervisors are exhibiting the same behaviors, implicit biases can influence perceptions 
such that younger supervisors benefit from not adhering to expectations, and older supervisors are penalized. This is in line with the findings of this study relating younger supervisors to higher employee-reports of LMX.

As expected based on previous research (e.g., Dulebohn et al., 2012), the link between LMX and job satisfaction was supported. Significant results indicate that LMX quality predicts level of job satisfaction six months later. This makes sense because we know that LMX is stable over time and that leaders control and influence numerous job characteristics that impact job satisfaction (e.g., Dulebohn et al., 2012; Liden, Wayne, \& Stilwell, 1993). An indirect effect was also revealed such that employees with younger supervisors reported higher LMX and in turn had higher job satisfaction six months later.

Although it was expected that LMX would also predict life satisfaction, this hypothesis was not supported. It is possible that life satisfaction is too distal a construct, and that many other factors play a more important role in determining life satisfaction (e.g., Erdogan et al., 2012). LMX was also expected to predict retirement intentions. Although the results were in the expected direction, they were not significant $(p=.30)$, and therefore this hypothesis was rejected. Many factors influence retirement intentions (e.g., Szinovacz, 2003), but LMX does not appear to be one of these. These findings contribute to the current literature by directing researchers to explore other factors that are likely to have a larger effect on life satisfaction and retirement intentions.

\section{Implications for Research and Practice}

The primary implication of this study is that age differences between supervisors and employees are either not important, or are related in ways more complicated than 
similar is good and different is bad. Response surface trends indicate supervisor and employee age similarity may actually be detrimental when employees are around middle age (mean was 44 years of age in this sample). This can be interpreted by combining the relational demography framework with implicit assumptions about social roles.

Researchers may want to further investigate if age and role categories are particularly salient at certain ages, and for certain outcomes. Relational demography researchers should also follow the advice of Harrison and colleagues (2002) and look at deeper-level characteristics used for categorization. Furthermore, future studies should investigate if dyad age difference effects are influenced by the age dispersion of other group members (e.g., Davis, 1966) or with different measures of age, such as subjective age (e.g., Rubin \& Bernsten, 2006).

Additionally, contrary to expectations that better outcomes would be associated with older supervisors managing younger employees, adherence to these implicit social roles is not associated with more positive outcomes. Actually, it appears that matching older workers with younger supervisors could be a potential leverage point to improve job satisfaction and delay retirement intentions of older workers. A better understanding of this is needed to drive research and practice. It is possible that implicit assumptions about social and organizational roles have shifted over time (Truxillo, Finkelstein et al., 2015), and/or that they are very dependent on prototype matching (Perry, 1993).

Different expectations for supervisors of different age groups possibly leads to a positive bias for younger supervisors and a negative bias for older supervisors (Tsui et al., 1989; Zacher et al., 2011). The findings of this study indicate that implicit assumptions may not 
function as expected and support Zacher and colleagues (2011) finding that biases have different effects for different age groups. Researchers should investigate the content of implicit assumptions about career timelines, as well as leader and performer characteristics. Moreover, more studies should examine how the content of these assumptions results in different outcomes for supervisors of different ages.

Context is a major consideration when interpreting these results and planning future directions. Individual, organizational, and social culture can all impact perceptions and attitudes about different age groups within a work setting. The previous studies discussed here have covered multiple industries (e.g, professors and grounds keepers) as well as global regions (United States and Mexico). The current study added municipal construction workers in the U.S, however more in depth attention to how these contextual influences differently impact bias is needed to inform best practices for intervention.

Finally, results revealing employee-rated LMX was higher when supervisors were younger imply that assessing age bias in organizations is very important. Although it cannot be concluded that these results reflect bias against older workers, it is a possible explanation and one that can be assessed in future research with measures of implicit and explicit attitudes about age and stereotypes. This indicates a potential leverage point for organizational intervention to improve numerous outcomes related to LMX (Erdogan \& Bauer, 2014), including job satisfaction as demonstrated here. Trainings to reduce implicit biases and promotion of positive age diversity climates are potential strategies for organizations and researchers to explore in order to promote high-quality relationships between employee and supervisor dyads of all age groupings. Targeted 
esearch and interventions should be conducted and tested to determine how bias can be reduced and the associated effects attenuated.

\section{Limitations and Future Directions}

The sample used to examine these hypotheses creates several limitations. First, generalizability is an issue because participants were primarily white males, and all were construction workers. Although the use of a blue-collar sample is a contribution of this study in itself, in the future, attempts should be made to assess a more diverse population. An additional limitation is that the sample was skewed in the direction of a much greater number of supervisors older than employees as compared to supervisors younger than their employees. Future research on this phenomenon should identify a sample with a more symmetric age difference distribution. However, it should be noted that range restriction was not a limitation as age variability was good within both employee and supervisor groups. The nature of this sample's work (e.g., physical demands), particular health issues such as an increased risk of cardiovascular disease (Bodner et al., 2014) and government pension plans likely play a role in retirement decisions above and beyond attitudinal preferences and were not accounted for. Additionally, these data are limited by use of only one self-report item measuring health. These factors should be considered in any future research with this type of population.

Common-method bias resulting from use of all self-report measures is a limitation for all findings. This limitation should be addressed in the future by including objective measures such as blood pressure and salary as these are likely to relate to both life satisfaction and retirement. Collecting measures for supervisors in addition to employees 
would also be helpful for addressing common-method bias, but also important since supervisor experiences are often ignored in organizational research. Additionally, future research needs to assess how different age groups think about retirement and develop standards guiding which age these attitudes should begin to be measured.

The study design used here only investigated the relationship between LMX and job satisfaction, life satisfaction, and retirement intentions in one direction. Recently, Volmer and colleagues (2011) revealed a reciprocal relationship between LMX and job satisfaction. It is possible that a relationship exists between LMX and life satisfaction and retirement intentions in the opposite direction of that proposed and tested. Researchers may want to examine this.

Although significant findings were not demonstrated here, the sample size was small in comparison to the number of parameters estimated. A larger sample, particularly one with more groups and a wider range of supervisor ages and age difference distribution might reveal different results. This is particularly relevant for retirement intentions due to a reduced sample size and results approaching significance. Additionally, the complexity of the polynomial regression approach and possibility of bias resulting from multicollinearity of regression terms limits drawing conclusions. Cross-validation is necessary (Yang, Levine, Smith, Ispas, \& Rossi, 2008). Another limitation is that $r$-squared estimates were not reported due to anomalous results. True rsquared values cannot be obtained in multilevel modeling and efforts to estimate pseudo r-squared can lead to uninterpretable results as was discovered with this data (e.g., Kreft \& De Leeuw, 1998). For example, this can occur when within- and between-group 
relationships with the outcome exist in different directions. Finally, it must also be noted that the outcomes examined are quite distal to the phenomenon of age differences, and global, in the sense that they are not directly related to the supervisor/subordinate relationship. It would be useful for future researchers to explore more proximal and relational outcomes, for example, trust, perceived justice, and organizational citizenship behaviors.

Researchers should work to develop a better understanding of this linkage between supervisor age and job satisfaction through LMX. Specifically, mediators and moderators of the indirect effect should also be explored. For instance, the relationship between supervisor age and LMX may be attenuated by a positive age diversity climate or exasperated by negative stereotypes. Additionally, research examining prototypes and prescriptive stereotypes in relation top supervisor age and LMX could help inform context-specific strategies for improving employee and supervisor relationships. It might also prove informative examine if organizational role of either party changed during their time working together (for example, supervisor was promoted within the team). Finally, based on findings contrary to those proposed by implicit social role theories, researchers should use implicit association testing (Nosek et al., 2007) to investigate the content of implicit assumptions about age and social roles, particularly related to work role prototypes within and across industries.

\section{Conclusion}

In conclusion, an aging workforce and increasing age heterogeneity calls for a greater understanding of how age diversity impacts work processes and outcomes. The 
current study used up-to-date statistical methodologies to reexamine linkages between age (in)congruence with job satisfaction and LMX, and to examine the relationship between age (in)congruence with life satisfaction and retirement intentions. Results reveal that both directional and nondirectional age differences do not predict these outcomes. It is noted that some estimates approached significance, and given the sample size and number of parameters estimated, researchers may want to reinvestigate the novel linkages introduced. A main effect of supervisor age on LMX was discovered, such that LMX quality was higher across employee ages when supervisors were younger (on a spectrum of younger to older). Finally, an indirect effect was found between supervisor age and job satisfaction through LMX. Future research should investigate the content of implicit biases and how these impact perceptions and effectiveness of older and younger leaders. This information is needed to inform interventions so that business can structure the workplace to maximize benefits for individuals, teams, and the organization. 


\section{Tables}

Table 1

Survey Measures

Job Satisfaction (Cammann et al., 1983; $\alpha=.85$ )

Instructions: Please read each of the following statements and choose how much you agree or disagree with each one. (Strongly Disagree =1; Strongly Agree = 5)

1. In general, you like working at your job.

2. In general, you are satisfied with your job.

3. You are generally satisfied with the kind of work you do in this job.

Life Satisfaction (Diener et al., 1985; $\alpha=.90$ )

Instructions: Please read each of the following statements and choose how much you agree or disagree with each one. (Strongly Disagree $=1$; Strongly Agree = 5)

1. In most ways my life is close to my ideal.

2. I am satisfied with my life.

3. The conditions of my life are excellent.

4. So far, I have gotten the important things I want in my life.

5. If I could live my life over, I would change almost nothing.

Preference to Retire (Adapted from Hom et al., 1984; $\alpha=.86$ )

Read each statement carefully. Then, for each statement fill in the bubble that best represents your current view of retirement. Please choose only one answer for each question. (Strongly Disagree = 1;

Strongly Agree = 5)

1. I often think about retiring.

2. If I have my own way, I will be retiring a year from now.

3. If I had my own way, I would retire soon.

Leader-Member Exchange (LMX7; Scandura \& Graen, 1984; $\alpha=.92)$

1. Do you know where you stand with your supervisor? (Rarely $=1$; Very Often $=5$ )

2. How well does your supervisor understand your job problems and needs? (Not a Bit = 1; A Great Deal $=5)$

3. How well does your supervisor recognize your potential? (Not at All =1; Fully $=5$ )

4. Regardless of how much formal authority he/she has built into his/her position, what are the chances that your supervisor would use his/her power to help you solve problems in your work? (None $=1$; Very High = 5)

5. Again, regardless of the amount of formal authority your supervisor has, what are the chances that he/she would "bail you out," at his/her expense? (None = 1; Very High = 5)

6. I have enough confidence in my supervisor that I would defend and justify his/her decision if he/she were not present to do so. (Strongly Disagree = 1; Strongly Agree = 5)

7. How would you characterize your working relationship with your supervisor? (Extremely Ineffective

$=1 ;$ Extremely Effective = 5) 
AGE DIFFERENCES AND LMX

Table 2

Descriptive Statistics, Correlations, and Alpha Reliabilities

\begin{tabular}{|c|c|c|c|c|c|c|c|c|c|}
\hline & $n$ & $M$ & $S D$ & 1 & 2 & 3 & 4 & 5 & 6 \\
\hline 1. LMX (Time 1) & 332 & 3.19 & 0.87 & $(.92)$ & & & & & \\
\hline 2. Job Satisfaction (Time 2) & 297 & 3.97 & 0.68 & $\begin{array}{c}.41 * \\
*\end{array}$ & $(.85)$ & & & & \\
\hline 3. Life Satisfaction (Time 2) & 291 & 3.32 & 0.82 & .10 & $\begin{array}{c}.30^{*} \\
*\end{array}$ & $(.90)$ & & & \\
\hline 4. Retirement Intentions (Time 2) & 182 & 3.51 & 1.13 & -.08 & $.25^{-}$ & -.09 & $(.84)$ & & \\
\hline 5. Employee Age & 419 & $\begin{array}{c}44.3 \\
7\end{array}$ & 9.76 & -.06 & .03 & $-.19 *$ & .11 & & \\
\hline 6. Supervisor Age $(k=23)$ & 264 & $\begin{array}{c}50.3 \\
3\end{array}$ & 7.15 & $\begin{array}{c}.30^{*} \\
*\end{array}$ & .00 & .07 & -.11 & .08 & \\
\hline 7. Work Group & 419 & $\begin{array}{c}119 . \\
53\end{array}$ & $\begin{array}{c}10.8 \\
0\end{array}$ & -.48 & $-.12 *$ & .05 & .02 & -.03 & ${ }^{-}$. \\
\hline 8. Organizational Indicator & 419 & 0.42 & 0.49 & -.03 & $.12 *$ & .02 & -.02 & $-.09 \dagger$ & $-.38^{*}$ \\
\hline 9. Treatment Condition & 419 & 0.60 & 0.49 & $-.09 \dagger$ & -.07 & -.07 & -.01 & -.05 & $-.13 *$ \\
\hline 10. General Health (Time 2) & 288 & $\begin{array}{c}65.6 \\
6\end{array}$ & $\begin{array}{c}23.1 \\
8\end{array}$ & $.11 \dagger$ & $.10 \dagger$ & $\begin{array}{c}.34 * \\
*\end{array}$ & -.08 & -.10 & .06 \\
\hline 11. Tenure (Time 2) & 221 & 9.37 & 7.48 & -.05 & -.05 & $-.17^{*}$ & $\begin{array}{c}.29 * \\
*\end{array}$ & $\begin{array}{c}.48 * \\
*\end{array}$ & -.30 \\
\hline 12. Gender (Time 2) & 296 & 1.10 & 0.30 & .03 & -.03 & -.03 & .03 & .06 & .12 \\
\hline
\end{tabular}

Cronbach's Alpha for scale measures reported on diagonal (no value indicates single item).

Retirement intentions using a subset of only employees aged 40 and older. Employee ages range 19-72 years old. Supervisor ages range 38-64 years old.

$* * p<0.01, * p<0.05, \dagger p<0.10 . N=419$. 
Table 2 Continued

\begin{tabular}{|c|c|c|c|c|c|c|c|c|}
\hline & $n$ & $M$ & $S D$ & 7 & 8 & 9 & 10 & 11 \\
\hline 1. LMX (Time 1) & 332 & 3.19 & 0.87 & & & & & \\
\hline 2. Job Satisfaction (Time 2) & 297 & 3.97 & 0.68 & & & & & \\
\hline 3. Life Satisfaction (Time 2) & 291 & 3.32 & 0.82 & & & & & \\
\hline 4. Retirement Intentions (Time 2) & 182 & 3.51 & 1.13 & & & & & \\
\hline 5. Employee Age & 419 & 44.37 & 9.76 & & & & & \\
\hline 6. Supervisor Age $(k=23)$ & 264 & 50.33 & 7.15 & & & & & \\
\hline 7. Work Group & 419 & $\begin{array}{c}119.5 \\
3\end{array}$ & 10.80 & & & & & \\
\hline 8. Organizational Indicator & 419 & 0.42 & 0.49 & $.85 * *$ & & & & \\
\hline 9. Treatment Condition & 419 & 0.60 & 0.49 & $-.09 \dagger$ & .07 & & & \\
\hline 10. General Health (Time 2) & 288 & 65.66 & 23.18 & .01 & .01 & .03 & & \\
\hline 11. Tenure (Time 2) & 221 & 9.37 & 7.48 & $-.13 \dagger$ & $-.13 *$ & -.09 & $-.16^{*}$ & \\
\hline 12. Gender (Time 2) & 296 & 1.10 & 0.30 & .10 & .08 & -.08 & -.05 & .00 \\
\hline
\end{tabular}

Cronbach's Alpha for scale measures reported on diagonal (no value indicates single item)

Retirement intentions using a subset of only employees aged 40 and older. Employee ages range 19-72 years old. Supervisor ages range 38-64 years old.

$* * p<0.01, * p<0.05, \dagger p<0.10 . N=419$. 
Table 3

Cross-level Polynomial Regression and Response Surface Test Results

\begin{tabular}{|c|c|c|c|c|}
\hline Variables & LMX & $\begin{array}{c}\text { Job } \\
\text { Satisfaction }\end{array}$ & $\begin{array}{c}\text { Life } \\
\text { Satisfaction }\end{array}$ & $\begin{array}{l}\text { Retirement } \\
\text { Intentions }\end{array}$ \\
\hline Constant & $3.78 * * *$ & $3.96 * * *$ & $2.70 * * *$ & $3.72 * * *$ \\
\hline Treat & $-.35 *$ & .04 & -.16 & -.07 \\
\hline Org & $-.25 \dagger$ & $-.25 \dagger$ & .04 & -.21 \\
\hline Health & & & $0.01 * * *$ & \\
\hline Employee Age $\left(b_{1}\right)$ & -.01 & .01 & -.01 & .05 \\
\hline Supervisor Age $\left(b_{2}\right)$ & $-.07 * * *$ & -.02 & .01 & .02 \\
\hline Employee $\operatorname{Age}^{2}\left(b_{3}\right)$ & .00 & .00 & .00 & .00 \\
\hline $\begin{array}{l}\text { Employee Age*Supervisor Age } \\
\left(b_{4}\right)\end{array}$ & .00 & .00 & .00 & .00 \\
\hline Supervisor $\operatorname{Age}^{2}\left(b_{5}\right)$ & .00 & .00 & .00 & $.00 \dagger$ \\
\hline \multicolumn{5}{|l|}{ Congruence Line $(\mathrm{E}=\mathrm{S})$} \\
\hline Slope: $b_{1}+b_{2}$ & $-.08 * * *$ & -.01 & .00 & .07 \\
\hline Curvature: $b_{3}+b_{4}+b_{5}$ & $.00 \dagger$ & .00 & .00 & -.01 \\
\hline \multicolumn{5}{|l|}{ Incongruence Line $(E=-S)$} \\
\hline Slope: $b_{1}-b_{2}$ & $.06 * *$ & .03 & -.02 & .03 \\
\hline Curvature: $b_{3}-b_{4}+b_{5}$ & .00 & .00 & .00 & -.01 \\
\hline
\end{tabular}


Figures

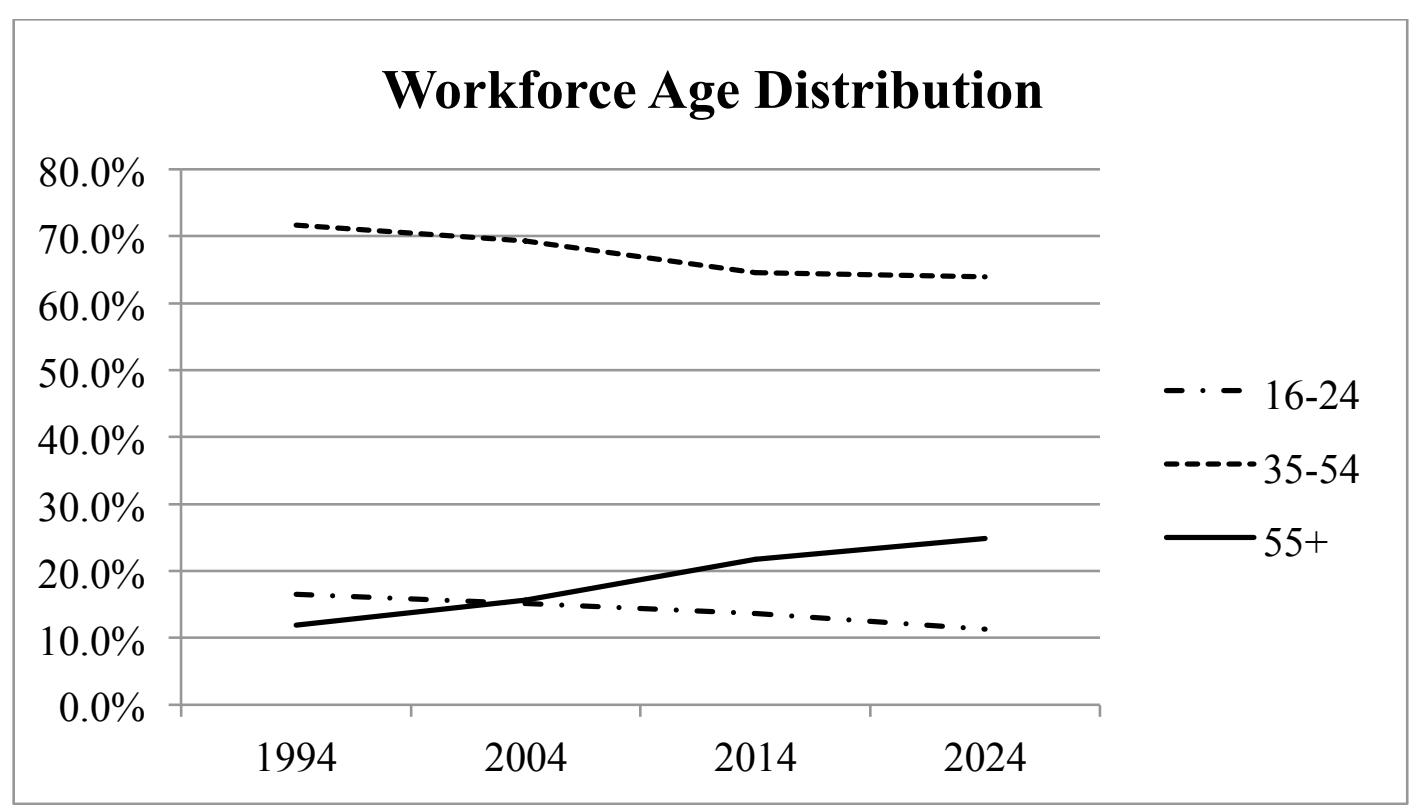

Figure 1. Changes over time in the age distribution of the workforce (Toossi, 2015). 


\section{Workforce Age Distribution \\ 1994}

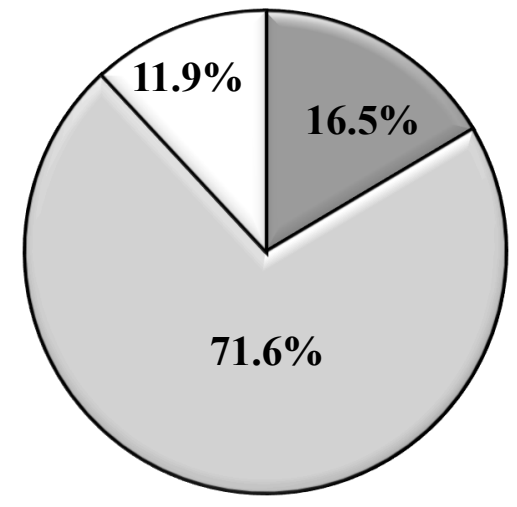

Age in Years

$\square 16-24 \quad \square 35-54 \quad \square 55+$
Workforce Age Distribution 2024

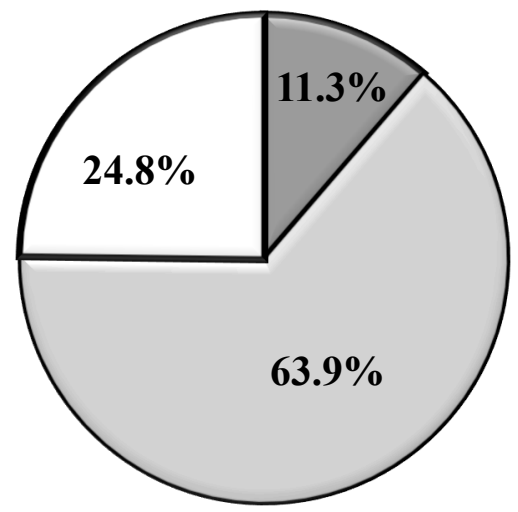

Age in Years

口16-24 35-54 口55+

Figure 2. Workforce age distribution in 1994 as compared to projection for 2024 (Toosi, 2015). 
Running head: AGE DIFFERENCES AND LMX

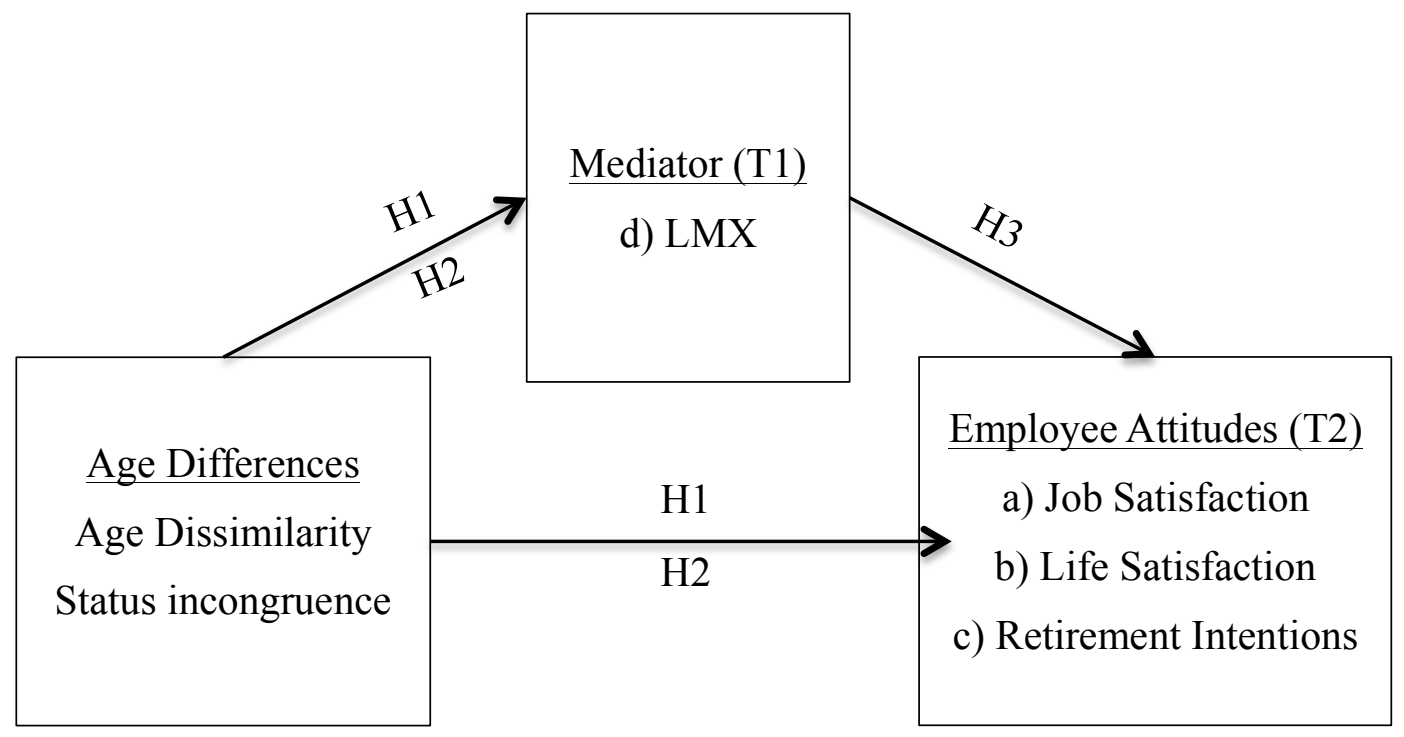

H4: LMX as mediator

Figure 3. Conceptual model. 


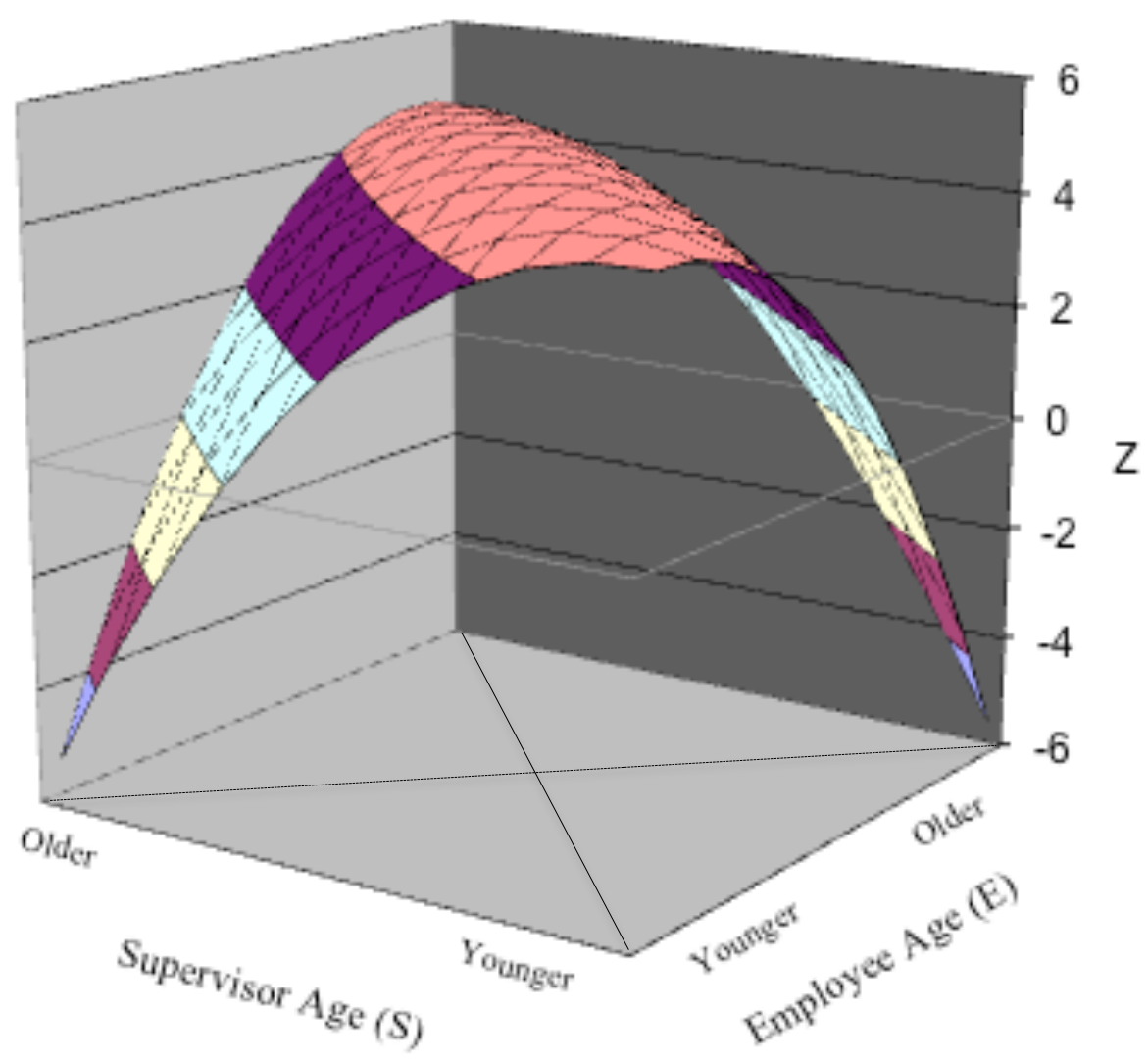

Figure 4. Example response surface for congruence effect. Note the flat surface along the line of congruence $(\mathrm{E}=\mathrm{S}$ represented by solid line) and negative curvature along the line of incongruence $(\mathrm{E}=-\mathrm{S}$ represented by dashed line). This image illustrates outcome $\mathrm{Z}$ is maximized when Employee Age and Supervisor Age are equal and that $Z$ decreases as the discrepancy between Employee Age and Supervisor Age increase in either direction. 


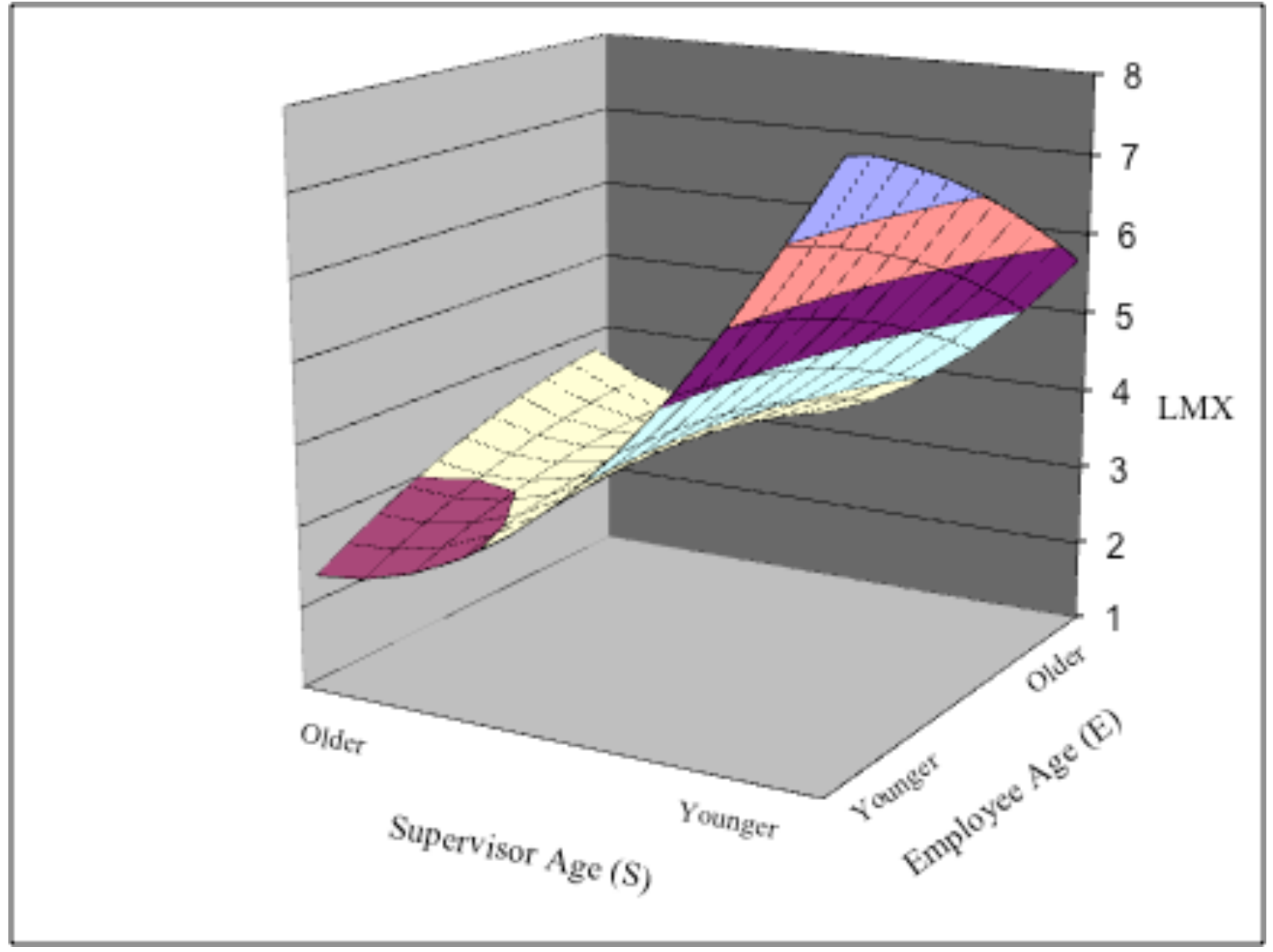

Figure 5. Response surface depicting the relationship between employee and supervisor age with LMX. LMX is higher when supervisors are younger, in general (right side of the graph). Interaction effects between employee and supervisor age are not significant. 


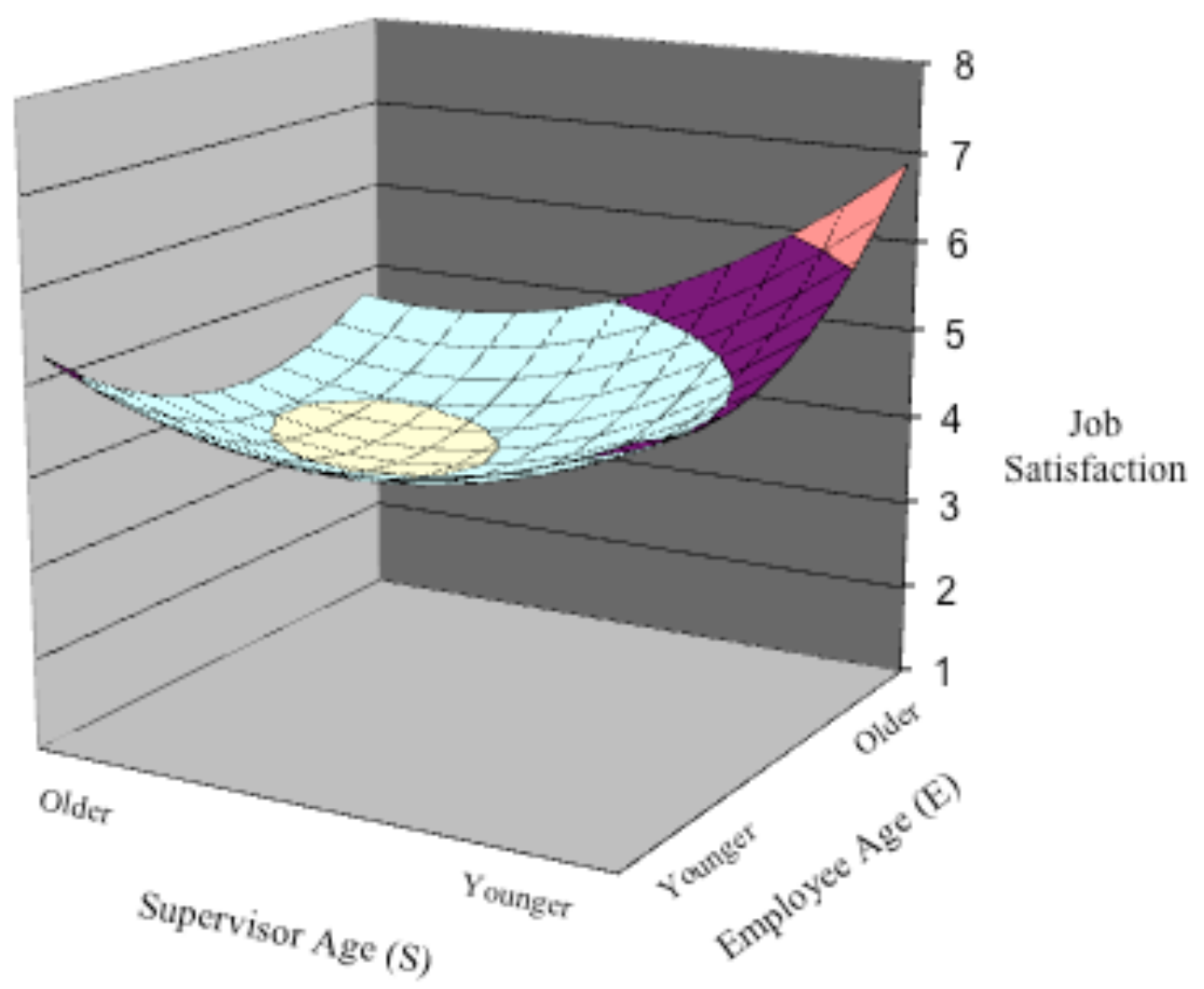

Figure 6. Response surface depicting the relationship between employee and supervisor age with Job Satisfaction. Job satisfaction appears to be somewhat higher when employees and supervisors are different ages, with the highest job satisfaction being reported when employees are older than their supervisors (back, right quadrant). Interaction effects between employee and supervisor age are not significant. 


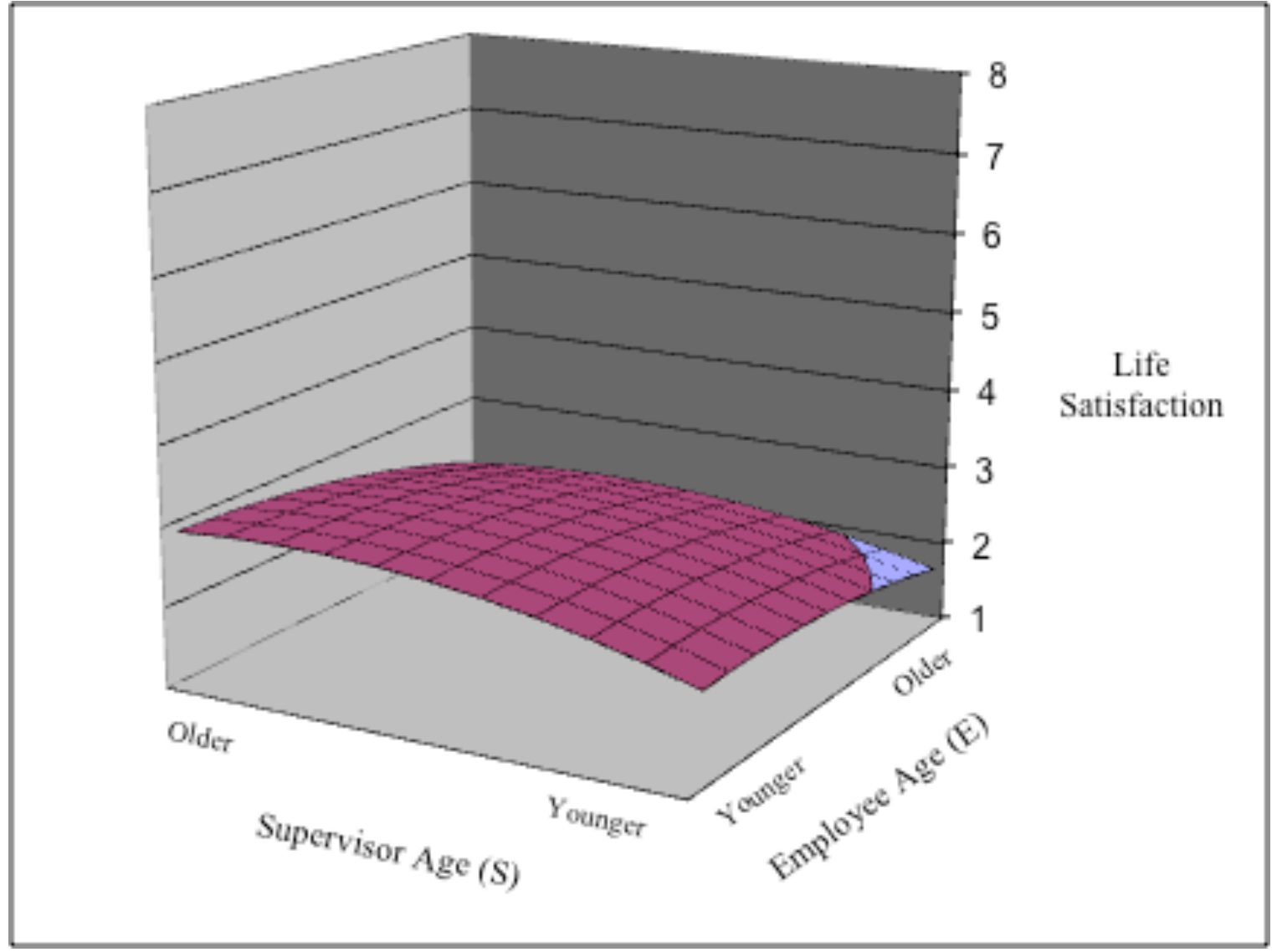

Figure 7. Response surface depicting the relationship between employee and supervisor age with Life Satisfaction. The graph is rather flat indicating there is not an effect between employee and supervisor age on life satisfaction. Interaction effects between employee and supervisor age are not significant. 


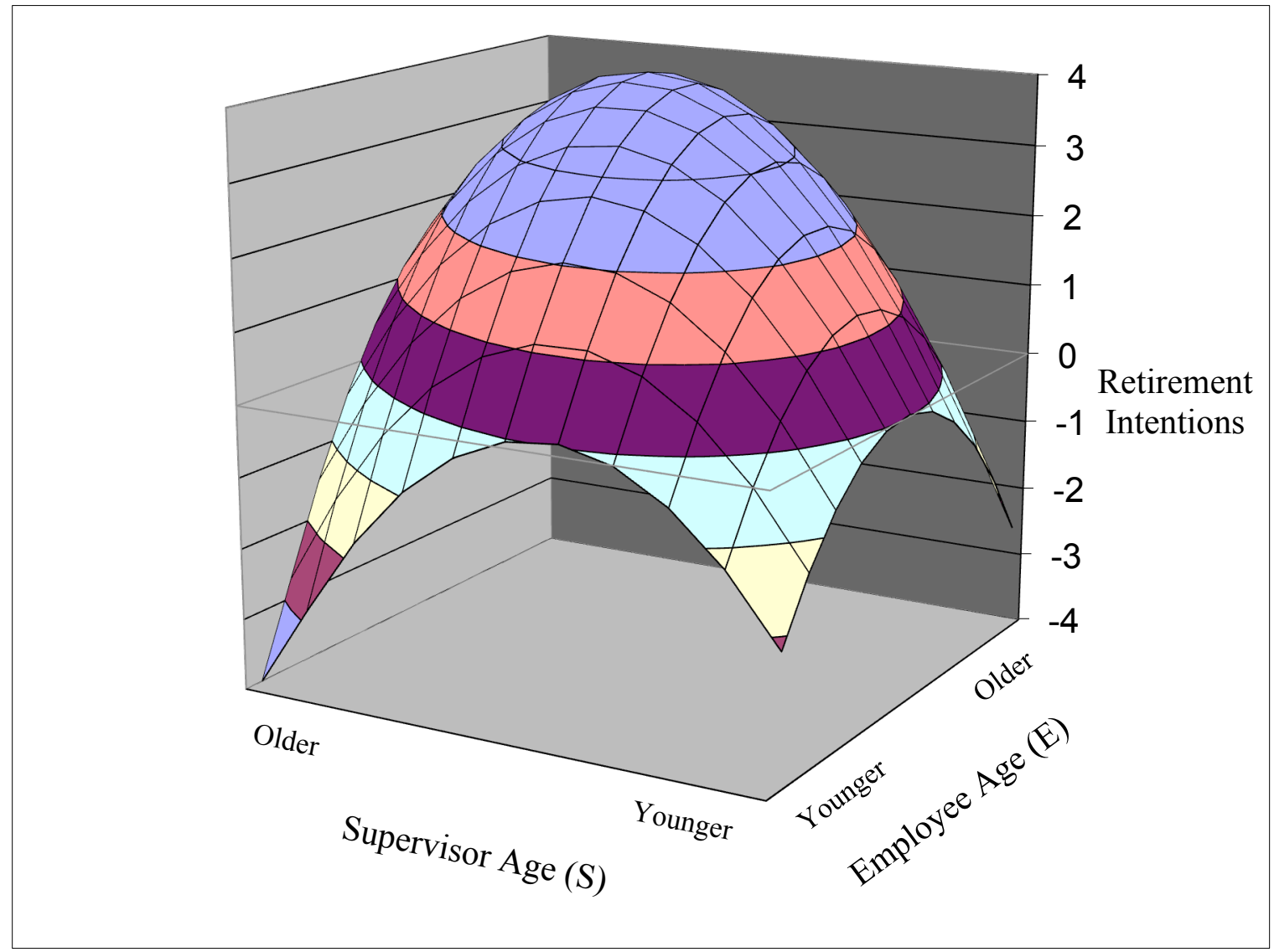

Figure 8. Response surface depicting the relationship between employee and supervisor age with Retirement Intentions. This image suggests that retirement intentions are highest when employees and supervisors are similar in age, and around middle age. Retirement intentions are lower when greater age differences exist (front, left quadrant and back, right quadrant). Interaction effects between employee and supervisor age are not significant. 
Running head: AGE DIFFERENCES AND LMX

References

Adams, J. S. (1963). Towards an understanding of inequity. The Journal of Abnormal and Social Psychology, 67, 422-436. DOI: 10.1037/h0040968

Adams, J. S. (1965). Inequity in social exchange. Advances in Experimental Social Psychology, 2, 267-299.

Allen, T. D. (2001). Family-supportive work environments: The role of organizational perceptions. Journal of Vocational Behavior, 58, 414-435. DOI:10.1006/jvbe.2000.1774,

Arsenault, P. M. (2004). Validating generational differences: A legitimate diversity and leadership issue. Leadership \& Organization Development Journal, 25, 124-141. DOI $10.1108 / 01437730410521813$

Baltes, P. B. \& Baltes, M. M. (1990). Psychological perspectives on successful aging: The model of selective optimization with compensation. In P. B. Baltes and M. M. Baltes (Eds.), Successful aging: Perspectives from the behavioral sciences (pp. 1-34). New York: Cambridge University Press.

Barnes-Farrell, J. L. (2003). Beyond health and wealth: Attitudinal and other influences on retirement decision-making. In G. A. Adams \& T. A. Beehr (Eds.), Retirement: Reasons, processes, and results (pp. 59-187). New York: Springer Publishing Company.

Baron, R. M., \& Kenny, D. A. (1986). The moderator-mediator variable distinction in social psychological research: Conceptual, strategic, and statistical considerations. Journal of Personality and Social Psychology, 51, 1173-1182.

DOI: $10.1037 / 0022-3514.51 .6 .1173$ 
Running head: AGE DIFFERENCES AND LMX

Bassett-Jones, N. (2005). The paradox of diversity management, creativity and innovation. Creativity and Innovation Management, 14, 169-175.

DOI: $10.1111 / j .1467-8691.00337 . x$

Bedeian, A. G., Ferris, G. R., \& Kacmar, K. M. (1992). Age, tenure, and job satisfaction: A tale of two perspectives. Journal of Vocational Behavior, 40, 33-48. DOI: $10.1016 / 0001-8791(92) 90045-2$

Beehr, T. A. (1986). The process of retirement: A review and recommendations for future investigation. Personnel Psychology, 39, 31-55. DOI: 10.1111/j.17446570.1986.tb00573.x

Beehr, T. A. (2014). To retire or not to retire: That is not the question. Journal of Organizational Behavior, 35, 1093-1108. DOI: 10.1002/job.1965

Bell, L. M. (1994). Looking for passages through the glass ceiling: An empirical field investigation into the effects of gender, age and leader-member exchange relationships on the career progress and career perceptions of working professionals (Doctoral dissertation). University of Cincinnati, Cincinnati, $\mathrm{OH}$.

Biddle, B. J. (1986). Recent development in role theory. Annual Review of Sociology, 12, $67-92$.

Bodner, T., Kraner, M., Bradford, B., Hammer, L., \& Truxillo, D. (2014). Safety, health, and well-being of municipal utility and construction workers. Journal of Occupational and Environmental Medicine, 56, 771-778. DOI: 10.1097/JOM.0000000000000178

Bowling, N. A., \& Hammond, G. D. (2008). A meta-analytic examination of the construct validity of the Michigan Organizational Assessment Questionnaire Job 
Running head: AGE DIFFERENCES AND LMX

Satisfaction Subscale. Journal of Vocational Behavior, 73, 63-77.

DOI:10.1016/j.jvb.2008.01.004

Brand, S., Beck, J., Hatzinger, M., Harbaugh, A., Ruch, W., \& Holsboer-Trachsler, E. (2010). Associations between satisfaction with life, burnout-related emotional and physical exhaustion, and sleep complaints. World Journal of Biological Psychiatry, 11, 744-754. DOI:10.3109/15622971003624205

Box, G. E. P., \& Draper, N. R. (1987). Empirical model-building and response surfaces. New York: Wiley.

Byrne D. (1971). The Attraction Paradigm. New York: Academic Press

Cadiz, D., Pytlovany, A. C., \& Truxillo, D. M. (in press). Ageism in the Workplace. Oxford Research Encyclopedia of Psychology. New York: Oxford University Press.

Cammann, C., Fichman, M., Jenkins, G. D., \& Klesh, J. (1983). Michigan Organizational Assessment Questionnaire. In S. E. Seashore, E. E. Lawler, P. H. Mirvis, \& C. Cammann (Eds.), Assessing organizational change: A guide to methods, measures, and practices (pp. 71-138). New York: Wiley.

Chida, Y., \& Steptoe, A. (2008). Positive psychological well-being and mortality: A quantitative review of prospective observational studies. Psychosomatic Medicine, 70, 741-756. DOI: 10.1097/PSY.0b013e31818105ba

Clark, A. E. (1997). Job satisfaction and gender: why are women so happy at work?. Labour Economics, 4, 341-372. DOI: 10.1016/S0927-5371(97)00010-9 
Running head: AGE DIFFERENCES AND LMX

Clark, M., \& Arnold, J. (2008). The nature, prevalence and correlates of generativity among men in middle career. Journal of Vocational Behavior, 73, 473-484. DOI: 10.1016/j.jvb.2008.09.002

Collins, M. H., Hair, J. F., \& Rocco, T. S. (2009). The older-worker-younger supervisor dyad: A test of the Reverse Pygmalion effect. Human Resource Development Quarterly, 20, 21-41. DOI: 10.1002/hrdq.20006

Cummings, A., Zhou, J., \& Oldham, G. R. (1993). Demographic differences and employee work outcomes: Effects on multiple comparison groups. Paper presented at the annual meeting of the Academy of Management, Atlanta, GA.

Davis, J. A. (1966). The campus as a frog pond: An application of the theory of relative deprivation to career decisions of college men. American journal of Sociology, 72, $17-31$.

Dansereau, F., Graen, G., \& Haga, W. J. (1975). A vertical dyad linkage approach to leadership within formal organizations: A longitudinal investigation of the role making process. Organizational Behavior and Human Performance, 13, 46-78. DOI: $10.1016 / 0030-5073(75) 90005-7$

Demerouti, E., Bakker, A. B., Nachreiner, F., \& Schaufeli, W. B. (2000). A model of burnout and life satisfaction amongst nurses. Journal of Advanced Nursing, 32, 454-464. DOI: 10.1046/j.1365-2648.2000.01496.x

Demerouti, E., Bakker, A. B., Nachreiner, F., \& Schaufeli, W. B. (2001). The job demands-resources model of burnout. Journal of Applied Psychology, 86, 499512. DOI: $10.1037 / 0021-9010.86 .3 .499$ 
Running head: AGE DIFFERENCES AND LMX

DeVaney, S. A., \& Kim, H. (2003). Older self-employed workers and planning for the future. Journal of Consumer Affairs, 37, 123-142. DOI: 10.1111/j.17456606.2003.tb00443.x

Diener, E., Emmons, R. A., Larsen, R. J., \& Griffin, S. (1985). The Satisfaction with Life Scale. Journal of Personality Assessment, 49, 71-75. DOI: 10.1207/s15327752jpa4901_13

Duckworth, A. L., Quinn, P. D., \& Seligman, M. E. P. (2009). Positive predictors of teacher effectiveness. Journal of Positive Psychology, 4, 540-547. DOI: $10.1080 / 17439760903157232$

Dulebohn, J. H., Bommer, W. H., Liden, R. C., Brouer, R. L., \& Ferris, G. R. (2012). A meta-analysis of antecedents and consequences of leader-member exchange integrating the past with an eye toward the future. Journal of Management, 38(6), 1715-1759. DOI: $10.1177 / 0149206311415280$

Dunegan, K. J., Duchon, D., \& Uhl-Bien, M. (1992). Examining the link between leadermember exchange and the subordinate performance: The role of task analyzability and variety as moderators. Journal of Management, 18, 59-76. DOI: $10.1177 / 014920639201800105$

Edwards, J. R. (2002). Alternatives to difference scores: Polynomial regression and response surface methodology. In F. Drasgow, Fritz \& N. Schmitt (Eds.), Measuring and analyzing behavior in organizations: Advances in measurement and data analysis. (pp. 350-400). San Francisco, CA, US: Jossey-Bass.

Edwards, J. R., \& Cable, D. M. (2009). The value of value congruence. Journal of Applied Psychology, 94, 654-677. DOI: 10.1037/a0014891 
Running head: AGE DIFFERENCES AND LMX

Edwards, J. R., \& Parry, M. E. (1993). On the use of polynomial regression equations as an alternative to difference scores in organizational research. Academy of Management Journal, 36, 1577-1613. DOI: 10.2307/256822

Epitropaki, O., \& Martin, R. (1999). The impact of relational demography on the quality of leader-member exchanges and employee's work attitudes and wellbeing. Journal of Occupational and Organizational Psychology, 72, 237-240.

DOI: $10.1348 / 096317999166635$

Epitropaki, O., \& Martin, R. (2005). From ideal to real: A longitudinal study of the role of implicit leadership theories on leader-member exchanges and employee outcomes. Journal of Applied Psychology, 90, 659-676. DOI: 10.1037/00219010.90.4.659

Erdogan, B., \& Bauer, T. N. (2014). Leader-member exchange (LMX) theory: The relational approach to leadership. In D. V. Day (Ed.), The Oxford Handbook of Leadership and Organizations. Oxford University Press.

Erdogan, B., Bauer, T. N., Truxillo, D. M., \& Mansfield, L. R. (2012). Whistle while you work a review of the life satisfaction literature. Journal of Management, 38, 10381083. DOI: $10.1177 / 0149206311429379$

Erdogan, B., \& Enders, J. (2007). Support from the top: supervisors' perceived organizational support as a moderator of leader-member exchange to satisfaction and performance relationships. Journal of Applied Psychology, 92, 321-330. DOI: $10.1037 / 0021-9010.92 .2 .321$

Fagenson-Eland, E. A., Baugh, S. G., \& Lankau, M. J. (2005). Seeing eye to eye: A dyadic investigation of relational demography on perceptions of mentoring 
Running head: AGE DIFFERENCES AND LMX

activities. Career Developmental International, 10, 460-477. DOI

$10.1108 / 13620430510620557$

Feldman, D. C. (1994). The decision to retire early: A review and conceptualization. Academy of Management Review, 19, 285-311. DOI: 10.5465/AMR.1994.9410210751

Feldman, D. C., \& Beehr, T. A. (2011). A three-phase model of retirement decision making. American Psychologist, 66, 193-203. DOI: 10.1037/a0022153

Ferris, G. R. (1985). Role of leadership in the employee withdrawal process: A constructive replication. Journal of Applied Psychology, 70, 777-781.

Festinger, L. (1954). A theory of social comparison processes. Human relations, 7, 117140. DOI: $10.1177 / 001872675400700202$

Fritz, M. S., \& MacKinnon, D. P. (2007). Required sample size to detect the mediated effect. Psychological Science, 18, 233-239. DOI: 10.1111/j.14679280.2007.01882.x

Glenn, N. D., Taylor, P. A., \& Weaver, C. N. (1977). Age and job satisfaction among males and females: A multivariate, multisurvey study. Journal of Applied Psychology, 62, 189.

Graen, G. B., Novak, M. A., \& Sommerkamp, P. (1982). The effects of leader-member exchange and job design on productivity and satisfaction: Testing a dual attachment model. Organizational Behavior and Human Performance Decision, $30,109-131$.

Graen, G. B., \& Scandura, T. A. (1987). Toward a psychology of dyadic organizing. Research in Organizational Behavior, 9, 175-208. 
Running head: AGE DIFFERENCES AND LMX

Graen, G. B., \& Uhl-Bien, M. (1995). Relationship-based approach to leadership: Development of leader-member exchange (LMX) theory of leadership over 25years: Applying a multi-level multi-domain perspective. The Leadership Quarterly, 6, 219-247.

Graen, G. B., \& Wakabayashi, M. (1994). Cross-cultural leadership-making: Bridging American and Japanese diversity for team advantage. In: H.C. Triandis, M.D. Dunnette, \& L.M. Hough (Eds.), Handbook of Industrial and Organizational Psychology (Vol. 4, pp. 415-446). New York: Consulting Psychologist Press.

Grandey, A. A. (2003). When "the show must go on": Surface acting and deep acting as determinants of emotional exhaustion and peer-rated service delivery. Academy of Management Journal, 46, 86-96. DOI: 10.2307/30040678

Green, S. G., Anderson, S. E., \& Shivers, S. L. (1996). Demographic and organizational influences on leader-member exchange and related work attitudes. Organizational Behavior and Human Decision Processes, 66(2), 203214. DOI: $10.1006 /$ obhd.1996.0049

Gordon, R. A, \& Arvey, R. D. (1986). Perceived and actual ages of workers. Journal of Vocational Behavior, 28, 21-28. DOI: 10.1016/0001-8791(86)90036-9

Haar, J. M., \& Roche, M. A. (2010). Family supportive organization perceptions and employee outcomes: The mediating effects of life satisfaction. International Journal of Human Resource Management, 21, 999-1014. DOI: $10.1080 / 09585191003783462$

Hackman, J. R., \& Oldham, G. R. (1976). Motivation through the design of work: Test of a theory. Organizational Behavior and Human Performance, 16, 250-279. 
Running head: AGE DIFFERENCES AND LMX

Harrison, D. A., \& Klein, K. J. (2007). What's the difference? Diversity constructs as separation, variety, or disparity in organizations. Academy of Management Review, 32, 1199-1228. DOI: 10.5465/AMR.2007.26586096

Harrison, D. A., Price, K. H., \& Bell, M. P. (1998). Beyond relational demography: Time and the effects of surface- and deep-level diversity on work group cohesion. Academy of Management Journal, 41, 96-107.

Harrison, D. A., Price, K. H., Gavin, J. H., \& Florey, A. T. (2002). Time, teams, and task performance: Changing effects of surface-and deep-level diversity on group functioning. Academy of Management Journal, 45, 1029-1045.

DOI: $10.2307 / 256901$

Hayes, A. F. (2009). Beyond Baron and Kenny: Statistical mediation analysis in the new millennium. Communication Monographs, 76, 408-420.

DOI: $10.1080 / 03637750903310360$

Hayes, A. F. (2013). Introduction to mediation, moderation, and conditional process analysis: A regression-based approach. New York: The Guilford Press.

Herzberg, F. (1966). Work and the nature of man. Cleveland: World Publishing Company.

Hom, P. W., Griffeth, R. W., \& Sellaro, C. L. (1984). The validity of Mobley's (1977) model of employee turnover. Organizational Behavior and Human Performance, 34, 141-174.

Hunt, J. W., \& Saul, P. N. (1975). The relationship of age, tenure, and job satisfaction in males and females. Academy of Management Journal, 18, 690-702. 
Running head: AGE DIFFERENCES AND LMX

Jansen, K. J., \& Kristof-Brown, A. L. (2005). Marching to the beat of a different drummer: Examining the impact of pacing congruence. Organizational Behavior and Human Decision Processes, 97, 93-105. DOI: 10.1016/j.obhdp.2005.03.005

Jones, M. D. (2006). Which is a better predictor of job performance: Job satisfaction or life satisfaction. Journal of Behavioral and Applied Management, 8, 20-42.

Judge, T. A., \& Ferris, G.R. (1993). Social context of performance evaluation decisions. Academy of Management Journal, 36, 80-105.

Kacmar, K. M., Carlson, D. S., \& Brymer, R. A. (1999). Antecedents and consequences of organizational commitment: A comparison of two scales. Educational and Psychological Measurement, 59, 976-994.

Kearney, E. (2008). Age differences between leader and followers as a moderator of the relationship between transformational leadership and team performance. Journal of Occupational and Organizational Psychology, 81, 803-811.

DOI:10.1348/096317907X256717

Kreft, G. G. \& De Leeuw, J. (1998). Introducing multilevel modeling. London: Sage Publications.

Kunze, F., Böhm, S. A., \& Bruch, H. (2011). Age diversity, age discrimination climate and performance consequences - a cross organizational study.Journal of Organizational Behavior, 32, 264-290. DOI: 10.1002/job.698

LaGrace, R. R., (1990). Leader-member exchange: Antecedents and consequences of the cadre and hired hand. Journal of Personal Selling and Sales Management, 10, 1119. 
Running head: AGE DIFFERENCES AND LMX

Lawrence, B. S. (1984). Age grading: The implicit organizational timetable. Journal of Organizational Behavior, 5, 23-35.

Lawrence, B. S. (1988) New wrinkles in the theory of age: Demography, norms, and performance ratings, Academy of Management Journal, 31, 309-337.

Liden, R. C., Wayne, S. J., \& Stilwell, D. (1993). A longitudinal study on the early development of leader-member exchanges. Journal of Applied Psychology, 78, 662. DOI: $10.1037 / 0021-9010.78 .4 .662$

Locke, E. A. (1976). The nature and causes of job satisfaction. In M.D. Dunnette (Ed.), Handbook of Industrial and Organizational Psychology (pp.1297-1343). Rand McNally: Chicago.

Lord, R. G., \& Maher, K. J. (1991). Cognitive theory in industrial and organizational psychology. Handbook of Industrial and Organizational Psychology, 2, 1-62.

Lord, R. G., De Vader, C. L., \& Alliger, G. M. (1986). A meta-analysis of the relation between personality traits and leadership perceptions: An application of validity generalization procedures. Journal of Applied Psychology, 71, 402-410.

Maybery, D. J., Neale, J., Arentz, A., \& Jones-Ellis, J. (2007). The Negative Event Scale: Measuring frequency and intensity of adult hassles. Anxiety, Stress \& Coping: An International Journal, 20, 163-176. DOI: 10.1080/10615800701217654

Mroczek, D. K., \& Spiro III, A. (2005). Change in life satisfaction during adulthood: Findings from the veterans affairs normative aging study. Journal of Personality and Social Psychology, 88, 189. DOI: 10.1037/0022-3514.88.1.189

National Institute of Occupational Research Agenda (2008, October 27). National construction agenda: For occupational safety and health research and practice in 
Running head: AGE DIFFERENCES AND LMX

the US construction sector. Retrieved from

http://www.cdc.gov/niosh/nora/comment/agendas/construction/pdfs/ConstOct200 8.pdf

Nosek, B. A., Smyth, F. L., Hansen, J. J., Devos, T., Lindner, N. M., Ranganath, K. A., ... Banaji, M. R. (2007). Pervasiveness and correlates of implicit attitudes and stereotypes. European Review of Social Psychology, 18, 36-88.

Nystrom, P. C. (1990). Vertical exchanges and organizational commitments of American business managers. Group \& Organization Management, 15, 296-312.

Offermann, L. R., Kennedy, J. K., \& Wirtz, P. W. (1994). Implicit leadership theories: Content, structure, and generalizability. Leadership Quarterly, 5, 43-58.

O'Reilly III, C. A., Caldwell, D. F., \& Barnett, W. P. (1989). Work group demography, social integration, and turnover. Administrative Science Quarterly, 34, 21-37.

Organization for Economic Cooperation and Development (OECD) Staff. (2013). Health at a Glance 2013: OECD Indicators. OECD Publishing. DOI: 10.1787/19991312

Osbeck, L. M., Moghaddam, F. M., \& Perreault, S. (1997). Similarity and attraction among majority and minority groups in a multicultural context. International Journal of Intercultural Relations, 21, 113-123.

Palmore, E., \& Luikart, C. (1972). Health and social factors related to life satisfaction. Journal of Health and Social Behavior, (13), 68-80.

Pavot, W. G., \& Diener, E. (1993). Review of the Satisfaction With Life Scale. Psychological Assessment, 5, 164-172.

Pelled, L. H. \& Xin, K. R. (2000). Relational demography and relational quality in two cultures. Organization Studies, 21, 1077-1094. 
Running head: AGE DIFFERENCES AND LMX

Perry, E. (1994). A prototype matching approach to understanding the role of applicant gender and age in the evaluation of job applicants. Journal of Applied Social Psychology, 24, 1433-1473.

Perry, E. L., Kulik, C. T., \& Zhou, J. (1999). A closer look at the effects of subordinatesupervisor age differences. Journal of Organizational Behavior, 20, 341-357.

Petersen, J. S., \& Zwerling, C. (1998). Comparison of health outcomes among older construction and blue-collar employees in the United States. American Journal of Industrial Medicine, 34, 280-287.

Rubin, D. C., \& Berntsen, D. (2006). People over forty feel $20 \%$ younger than their age: Subjective age across the lifespan. Psychonomic Bulletin \& Review, 13, 776-780.

Scandura, T. A., \& Graen, G. B. (1984). Moderating effects of initial leader-member exchange status on the effects of a leadership intervention. Journal of Applied Psychology, 69, 428-436.

Schaffer, B. S. \& Riordan, C. M. (2013). Relational demography in supervisorsubordinate dyads: An examination of discrimination and exclusionary treatment. Canadian Journal of Administrative Sciences, 30, 3-17. DOI: 10.1002/CJAS.1237

Seers, A., \& Graen, G. B. (1984). The dual attachment concept: A longitudinal investigation of the combination of task characteristics and leader-member exchange. Organizational Behavior \& Human Performance, 33, 283-306.

Senn, D. J. (1971). Attraction as a function of similarity-dissimilarity in task performance. Journal of Personality and Social Psychology, 18, 120. 
Running head: AGE DIFFERENCES AND LMX

Shaw, J. D., \& Gupta, N. (2001). Pay fairness and employee outcomes: Exacerbation and attenuation effects of financial need. Journal of Occupational and Organizational Psychology, 74, 299-320. DOI: 10.1348/096317901167370

Shore, L. M., Cleveland, J. N., \& Goldberg, C. B. (2003). Work attitudes and decisions as a function of manager age and employee age. Journal of Applied Psychology, 88, 529-537. DOI: 10.1037/0021-9010.88.3.529

Shultz, K. S., \& Wang, M. (2011). Psychological perspectives on the changing nature of retirement. American Psychologist, 66, 170. DOI: 10.1037/a0022411

Smith, P. C., Kendall, L. M., \& Hulin, C. (1969). The measurement of satisfaction in work and retirement: A strategy for the study of attitudes. Chicago: Rand McNally

Sobel, M. E. (1982). Asymptotic confidence intervals for indirect effects in structural equation models. Sociological Methodology, 13, 290-312.

Spector, P. E. (1997). Job satisfaction: Application, assessment, causes, and consequences. Thousand Oaks, CA: SAGE Publications, Inc.

Strine, T. W., Chapman, D. P., Balluz, L. S., Moriarty, D. G., \& Mokdad, A. H. (2008). The associations between life satisfaction and health-related quality of life, chronic illness, and health behaviors among US community-dwelling adults. Journal of Community Health, 33, 40-50. DOI 10.1007/s10900-007-9066-4

Sugiura, N. (1978). Further analysts of the data by akaike's information criterion and the finite corrections: Further analysts of the data by akaike's. Communications in Statistics-Theory and Methods, 7, 13-26. DOI: 10.1080/03610927808827599 
Running head: AGE DIFFERENCES AND LMX

Szinovacz, M. E. (2003). Contexts and pathways: Retirement as institution, process, and experience. In G. A. Adams \& T. A. Beehr (Eds.), Retirement: Reasons, processes, and results (pp. 6-52). New York: Springer Publishing Company.

Tajfel, H. \& Turner, J. C. (1986). The social identity theory of intergroup behavior. In S. Worchol \& W. G. Austin (Eds.), Psychology of Intergroup Relations (2nd ed). Chicago: Nelson-Hall.

Talaga, J. A., \& Beehr, T. A. (1995). Are there gender differences in predicting retirement decisions?. Journal of Applied Psychology, 80, 16.

Taylor, M. A., \& Shore, L. M. (1995). Predictors of planned retirement age: An application of Beehr's model. Psychology and Aging, 10, 76.

Thatcher, S. (1999). The contextual importance of diversity: The impact of relational demography and team diversity on individual performance and satisfaction. Performance Improvement Quarterly, 12, 97-112.

Thatcher, S., \& Patel, P. C. (2011). Demographic faultlines: A meta-analysis of the literature. Journal of Applied Psychology, 96, 1119. DOI: 10.1037/a0024167

Thomas, C. H., \& Lankau, M. J. (2009). Preventing burnout: The effects of LMX and mentoring on socialization, role stress, and burnout. Human Resource Management, 48(3), 417-432. DOI: 10.1002/hrm.20288

Toossi, M. (2015). Labor force projections to 2024: The labor force is growing, but slowly. Monthly Labor Review, 1-36. Retrieved from http://www.bls.gov/opub/mlr/2015/article/pdf/labor-force-projections-to-2024.pdf 
Running head: AGE DIFFERENCES AND LMX

Truxillo, D. M., \& Burlacu, G. (2015). Does age matter to LMX and its outcomes? A review and future research directions. In T. Bauer \& B. Erdogan (Eds.), Oxford Handbook of Leader-Member Exchange. New York: Oxford University Press.

Truxillo, D. M., Cadiz, D. E., \& Hammer, L. B. (2015). Supporting the aging workforce: A review and recommendations for workplace intervention research. Annual Review of Organizational Psychology and Organizational Behavior, 2, 351-381.

Truxillo, D. M., Finkelstein, L. M., Pytlovany, A. C., \& Jenkins, J. S. (2015). Age discrimination at work: A review of the research and recommendations for the future. In A. J. Colella \& E. B. King (Eds.), The Oxford Handbook of Workplace Discrimination. New York: Oxford University Press.

Truxillo, D. M., Cadiz, D. M., \& Rineer, J. R. (2014). The aging workforce: Implications for human resource management research and practice. In S. Jackson (Ed.), Oxford Handbooks Online: Business \& Management. DOI:

10.1093/oxfordhb/9780199935406.013.004

Tsui, A., Egan, T., \& O'Reilly III, C.A. (1992). Being different: Relational demography and organizational attachment. Administrative Science Quarterly, 37, 549-579.

Tsui, A., \& O'Reilly III, C.A. (1989). Beyond simple demographic effects: The importance of relational demography in superior-subordinate dyads. Academy of Management Journal, 32, 402-423.

Tsui, A. S., Xin, K. R., \& Egan, T. D. (1995). Relational demography: The missing link in vertical dyad linkage. In S. E. Jackson \& M. N. Ruderman (Eds.) Diversity in work teams: Research paradigms for a changing workplacce (pp. 97-129).

Washington, DC: American Psychological Association. 
Running head: AGE DIFFERENCES AND LMX

Turban, D. B., Jones, A. P., \& Rozelle, R. M. (1990). Influences of supervisor liking of a subordinate and the reward context on the treatment and evaluation of that subordinate. Motivation and Emotion, 14, 215-233.

Turner, J.C., \& Oakes, P.J., (1989). Self-categorization theory and social influence. In Turner, J.C., \& Oakes, P.J. (Eds.), Self-categorization theory and social influence. Hillsdale, NJ; Lawrence Erlbaum.

Van Dam, K., van der Vorst, J. D., \& van der Heijden, B. I. (2009). Employees' intentions to retire early a case of planned behavior and anticipated work conditions. Journal of Career Development, 35, 265-289.

Vecchio, R. P. (1993). The impact of differences in subordinate and supervisor age on attitudes and performance. Psychology and Aging, 8, 112.

Vecchio, R. P., Griffeth, R. W., \& Hom, P. W. (1986). The predictive utility of the vertical dyad linkage approach. The Journal of Social Psychology, 126, 617-625.

Volmer, J., Niessen, C., Spurk, D., Linz, A., \& Abele, A. E. (2011). Reciprocal relationships between leader-member exchange (LMX) and job satisfaction: A cross-lagged analysis. Applied Psychology, 60, 522-545.

Vroom, V. H. (1964). Work and motivation. New York: Wiley.

Wagner, W., Pfeffer, J., \& O'Reilly III, C.A. (1984). Organizational demography and turnover in top-management group. Administrative Science Quarterly, 29, 74-92.

Wang, M., Burlacu, G., Truxillo, D. M., James, K., \& Yao, X. (2015). Age differences in feedback reactions: The roles of feedback orientation on social awareness and utility. Journal of Applied Psychology. 
Running head: AGE DIFFERENCES AND LMX

Wang, M., \& Shi, J. (2014). Psychological research on retirement. Annual Review of

Psychology, 65, 209-233. DOI: 10.1146/annurev-psych-010213-115131

Wang, M., \& Shultz, K. S. (2010). Employee retirement: A review and recommendations for future investigation. Journal of Management, 36, 172-206. DOI:

$10.1177 / 0149206309347957$

Ware Jr, J. E., Kosinski, M., \& Keller, S. D. (1996). A 12 -item short-form health survey: Construction of scales and preliminary tests of reliability and validity. Medical Care, 34, 220-233.

Weiss, H. M., \& Cropanzano, R. (1996). Affective events theory: A theoretical discussion of the structure, causes and consequences of affective experiences at work. Research in Organizational Behavior, 18, 1-74.

Yang, L. Q., Che, H., \& Spector, P. E. (2008). Job stress and well-being: An examination from the view of person-environment fit. Journal of Occupational and Organizational Psychology, 81, 567-587. DOI: 10.1348/096317907X243324

Yang, L. Q., Levine, E. L., Smith, M. A., Ispas, D., \& Rossi, M. E. (2008). Personenvironment fit or person plus environment: A meta-analysis of studies using polynomial regression analysis. Human Resource Management Review, 18, 311321. DOI: $10.1016 /$ j.hrmr.2008.07.014

Zacher, H., Rosing, K., Henning, T. \& Frese, M. (2011.) Establishing the next generation at work: leader generativity as a moderator of the relationships between leader age, leader-member exchange, and leadership success. Psychology and Aging, (26), 241-252. DOI: 10.1037/a0021429 
Running head: AGE DIFFERENCES AND LMX

Zaniboni, S., Sarchielli, G., \& Fraccaroli, F. (2010). How are psychosocial factors related to retirement intentions?. International Journal of Manpower, 31, 271-285. DOI: $10.1080 / 1359432 X .2013 .782288$

Zhang, Z., Wang, M. O., \& Shi, J. (2012). Leader-follower congruence in proactive personality and work outcomes: The mediating role of leader-member exchange. Academy of Management Journal, 55, 111-130. DOI: 10.5465/amj.2009.0865 